\title{
Effect of Cu Incorporation on Optoelectronic Properties of e-Beam Evaporated ZnO thin Films by Ellipsometric Investigations
}

\section{Gharieb A Ali}

King Khalid University

said H. moustafa ( $\nabla$ s.moustafa@science.helwan.edu.eg)

Helwan University Faculty of Science https://orcid.org/0000-0002-5696-7064

\section{I. Amer}

Helwan University Faculty of Science

H. Shaban

National Research Centre

M. Emam-Ismail

Ain Shams University Faculty of Science

E. R. Shaaban

Al-Azhar University - Assiut Branch

\section{El-Hagary}

Helwan University Faculty of Science

\section{Research Article}

Keywords: spintronic applications, Magnetic semiconductors oxide, Nanocrystalline, surface topography, physical properties

Posted Date: March 16th, 2021

DOl: https://doi.org/10.21203/rs.3.rs-294805/v1

License: (a) (1) This work is licensed under a Creative Commons Attribution 4.0 International License. Read Full License 


\title{
Effect of $\mathrm{Cu}$ incorporation on optoelectronic properties of e-beam evaporated $\mathrm{ZnO}$ thin films by Ellipsometric investigations
}

\author{
Gharieb A. Ali ${ }^{1}$, S. H. Moustafa ${ }^{2 \S}$, M. I. Amer' ${ }^{2}$ H. Shaban ${ }^{3}$, M. \\ Emam-Ismail $^{4,5}$, E. R. Shaaban ${ }^{6}$, M. El-Hagary ${ }^{2}$ \\ ${ }^{1}$ Physics Department, Collage of Science\&Arta-Mahayel, King Khalid University, Saudi Arabia. \\ ${ }^{2}$ Physics Department, Faculty of Science, Helwan University, Helwan, 11792, Cairo, Egypt. \\ ${ }^{3}$ Solid State Physics Department, Physics Research Division, National Research Centre, Dokki, Giza, 12622, Egypt \\ ${ }^{4}$ Thin films laboratory, Physics Department, Faculty of Science, Ain Shams University, Cairo, 11566, Egypt. \\ ${ }^{5}$ Advanced Basic Science, Galala University, New Galala City, Suez, 43511, Egypt. \\ ${ }^{6}$ Physics Department, Faculty of Science, Al-Azhar University, Assiut, 71542, Egypt.
}

\begin{abstract}
Electron beam deposition technique has been used to deposit a series of $\mathrm{Zn}_{1-\mathrm{x}} \mathrm{Cu}_{\mathrm{x}} \mathrm{O}$ nanocrystalline thin film on silica substrate with a variety of $\mathrm{Cu}$ concentrations. The microstructural, surface morphology and spectroscopic ellipsometry (SE) were used to examine the physical properties of the deposited films. The nanocrystalline nature of the $\mathrm{Zn}_{1}$ ${ }_{\mathrm{x}} \mathrm{Cu}_{\mathrm{x}} \mathrm{O}(0.0 \leq \mathrm{x} \leq 0.20)$ thin film has been confirmed by surface morphology studies. The XRD spectrum of the $\mathrm{Zn}_{1-\mathrm{x}} \mathrm{Cu}_{\mathrm{x}} \mathrm{O}$ nanocrystalline film showed a hexagonal wurtzite type structure, and no extra phase was detected. Our results show that as the $\mathrm{Cu}$ content increases, the direct optical energy gap $E_{g}$ decreases without any sign of solubility limit up to $\mathrm{x} \leq 0.2$. The decrease in $E_{g}$ can be attributed to the sp-d exchange coupling. In addition, exploring the spectral behavior of the refractive index dispersion from $\mathrm{SE}$ of the $\mathrm{Cu}$-doped $\mathrm{ZnO}$ shows that as the $\mathrm{Cu}$ dopant increments; the refractive index of the deposited film enhances. Further, understand the refractive index dispersion of the deposited film has been performed using a single oscillator model proposed by Wemple-DiDomenico (WDD). Our calculations show that as the $\mathrm{Cu}$ concentration increases, the values of oscillator energy $E_{o}$ decreases however, the dispersion energy $E_{d}$ increases. As a result, the variation of the optical energy band gap and the tunability of the dispersive oscillator parameters values $E_{o}, E_{d}, n_{0}, \varepsilon_{0}, M_{-1}$ and $M_{-3}$ with the increase of the $\mathrm{Cu}$ doping level confirm that $\mathrm{Cu}$ doped $\mathrm{ZnO}$ films are a good candidate for optoelectronic device applications.
\end{abstract}

\section{Keywords:}

spintronic applications, Magnetic semiconductors oxide; Nanocrystalline, surface topography, physical properties.

${ }^{\S}$ Corresponding author S.H. Moustafa email: saidhuss2011@ @otmail.com; s.moustafa@science.helwan.edu.eg, Tel: +20 225590000-1798, Fax: +20225552468 


\section{1-Introduction}

Zinc oxide $(\mathrm{ZnO})$ is still a promising semiconductor, because it has a high exciton binding energy of $60 \mathrm{meV}$ at room temperature, direct wide band gap of $3.37 \mathrm{eV}$ [1], chemically stable, good transparency in the visible wavelength, high electronic conduction, good luminescence at room-temperature, cheap, and low toxicity matter. As a result of these fascinating properties, $\mathrm{ZnO}$ is very suitable for use in many applications, such as optoelectronic devices [2], photocatalysis [3], solar cells [4], UV fabric protectors [5] and gas sensing devices [6]. Many workers have already fabricated $\mathrm{ZnO}$ films using various techniques, including spray pyrolysis [7], reactive magnetron sputtering [8,9], chemical vapor deposition (CVD) [10], sol-gel [11] molecular beam epitaxy [12], and pulsed laser deposition $[13,14]$. Recently, a lot of researchers increase the potential of using $\mathrm{ZnO}$ by doping it with transition metals like $\mathrm{Fe}, \mathrm{Mn}, \mathrm{Co}, \mathrm{Ni}$ and $\mathrm{Cu}$ [15]. Among the family of transition metals, $\mathrm{Cu}$ is very important metal for doping due to its high electrical conductivity and almost similar ionic radii as that of $\mathrm{ZnO}$. Literature studies show that $\mathrm{Cu}$ doping into $\mathrm{ZnO}$ matrix can enhance its various physical, chemical and optical properties [16]. Commonly, doping causes the appearance of new acceptor levels and electron donors in the band structure of the doped

material. These levels appear in the gap, between the conduction band and the valence band $[17,18]$. The theoretical investigation shows that $\mathrm{Cu}$ doping can reduce band gap of $\mathrm{ZnO}$ leading to shift of the luminescence [19]. For copper doping, studies have shown that 5\%$10 \% \mathrm{Cu}$-doped $\mathrm{ZnO}$ has a lower band gap value than undoped $\mathrm{ZnO}[20,21]$. The crystallite size of the film increased as the doping ratio of $\mathrm{Cu}$ increased from 2 wt $\%$ to 10 wt $\%$. Increase in $\mathrm{Cu}$ doping leads to an insignificant decrease in the optical band gap of the thin films [22] and the nanoparticles were within the 32-38 $\mathrm{nm}$ range and the $\mathrm{Cu}$ dopant uniformly substituted $\mathrm{Zn}$ positions [23]. Other results show that $\mathrm{Cu}$ doping did not lead to the formation of a secondary phase, but slightly reduced the particle size [24] and the valence 
state of $\mathrm{Cu}$ in $\mathrm{ZnO}$ was confirmed to be +2 . It was found that the impurity level of $0.1 \%$ copper element is above the Fermi level, indicating that $\mathrm{Cu}$-doped $\mathrm{ZnO}$ is a p-type semiconductor [25].

The manuscript is summarized as follows:

- Part 2 describes the physical method used to produce and characterize nanocrystalline $\mathrm{Zn}_{1-\mathrm{x}} \mathrm{Cu}_{\mathrm{x}} \mathrm{O}(0.0 \leq \mathrm{x} \leq 0.2)$ in powder and thin film forms.

- Part 3 presents the structural and microstrcutural characteristics of nanostructured $\mathrm{Zn}_{1-\mathrm{x}} \mathrm{Cu}_{\mathrm{x}} \mathrm{O}(0.0 \leq \mathrm{x} \leq 0.2)$ thin films grown on silica glass substrates and morphology examination of the fixed-thickness nanostructured $\mathrm{Zn}_{1-\mathrm{x}} \mathrm{Cu} \mathrm{x}(0.0 \leq \mathrm{x} \leq 0.2)$ thin film by Atomic Force Microscopy (AFM)..

- In Part 4, the optical properties of nanostructured $\mathrm{Zn}_{1-\mathrm{x}} \mathrm{Cu}_{\mathrm{x}} \mathrm{Ofilm}$ with different $\mathrm{Cu}$ contents are comprehensively studied using the SE technique.

\section{Materials and Methods}

$\mathrm{Cu}$ doped $\mathrm{ZnO}$ ingots with different $\mathrm{Cu}$ concentrations $(0,4,8,12,16$, and 20 at.\%) have been synthesized using mechanical mailing method. Analytical grades with stoichiometric $\mathrm{ZnO}$ and $\mathrm{CuO}$ powders (with a chemical purity of (99.999\%, Aldrich) were mixed together and milled in a mechanical ball mill machine at $200 \mathrm{rpm}$ for 6 hours. The mixture is made into disk-shaped to avoid splashing the mixture powders during the evaporation process. The prepared pure and $\mathrm{Cu}$ doped $\mathrm{ZnO}$ ingots were used as a source for thin film deposition. The $\mathrm{ZnO}$ and $\mathrm{Cu}$ doped $\mathrm{ZnO}$ thin films with various $\mathrm{Cu}$ concentrations were deposited by electron beam evaporation technique (Edward Auto 306) at room temperature. Amorphous glass with a size of $(25 \mathrm{~mm} \times 25 \mathrm{~mm})$ is used as the substrate. To clean the substrate carefully, the substrate was immersed in acetone for 15 minutes, and then washed with purified water for 15 minutes, and subsequently with alcohol for 10 minutes. At 
last, the substrate was ultrasonically cleaned in deionised water for 15 minutes, and then was dried in air at a temperature of $100^{\circ} \mathrm{C}$. The substrates and ingots have been placed in the chamber, which was then evacuated at pressure of $5 \times 10^{-6} \mathrm{~Pa}$. The pellet ingot was preheated for 5 minutes before evaporation to remove any pollutants and degas the pellets. The distance from the substrate to the source is kept at about $20 \mathrm{~cm}$. The thickness of the film was adjusted at $300 \mathrm{~nm}$ at a deposition rate of $2 \mathrm{~nm} / \mathrm{sec}$, which was controlled by a thickness monitor device (model; FTM6). More details of the deposition methodology are explained elsewhere $[26,27,28,29,30,31,32]$.

\subsection{Characterization techniques}

$\mathrm{X}$-ray diffractometer (XRD, $\mathrm{Cu}-\mathrm{K} \alpha=1.54056 \AA$, Philips diffraction 1710$)$ was used for crystallographic investigation. The ratio of the elemental composition of the film was checked by using energy dispersive X-ray spectroscopy (EDXS). The surface morphology of the film was performed using an atomic force microscope (AFM, model MLCT-MT-A). The vertical resolution of the AFM device is about $0.2 \mathrm{~nm}$. The AFM cantilever is provided by NANO-WORLD, its cross-section is $4.5 \times 4.6 \mu \mathrm{m}^{2}$, the length is $160 \mu \mathrm{m}$, and it works at a resonant frequency of $285 \mathrm{kHz}$. Both sides of the cantilever are plated with platinum-iridium of about $\sim 23 \mathrm{~nm}$, and the tip is sharp with radius nearly less than $10 \mathrm{~nm}$. Non-contact mode is used to obtain the AFM image of the film surface. Optimized scan parameters is adjusted to supply the finest picture resolution whereas maintaining the speed and size of scan at 5 ms/pixel and $1 \times 1 \mu m^{2}$, respectively. The optical properties of nanostructured $\mathrm{Zn}_{1-\mathrm{x}} \mathrm{Cu}_{\mathrm{x}} \mathrm{O}$ $(0.0 \leq \mathrm{x} \leq 0.2)$ film were studied using variable-angle reflection $\mathrm{SE}$ instrument. SE apparatus has a revolving optical compensator and is also operational with a programmed retarder. The SE spectra is measured in the angular range $60^{\circ}-75^{\circ}$ with $5^{\circ}$ steps $[33,34,35]$. 


\section{Results and Discussions}

\subsection{Elemental composition analysis}

The elemental composition analysis of $\mathrm{Cu}$-doped $\mathrm{ZnO}$ films with different $\mathrm{Cu}$ doping levels has been performed by EDXS measurement. Fig. 1 represents the EDXS spectra ZnO, $\mathrm{ZnO}: \mathrm{Cu} 12$ at.\% and $\mathrm{ZnO}: \mathrm{Cu} 20$ at.\%. The spectra of the $\mathrm{Cu}$ doped films confirmed the appearance of three peaks corresponding to $\mathrm{Zn}, \mathrm{O}$, and $\mathrm{Cu}$. The spectra further show that the peak intensity of $\mathrm{Cu}$ increases with the increase of $\mathrm{Cu}$ doping, which indicates the stoichiometry of the film and $\mathrm{Cu}$ ions have been successfully incorporated into the $\mathrm{ZnO}$ matrix.
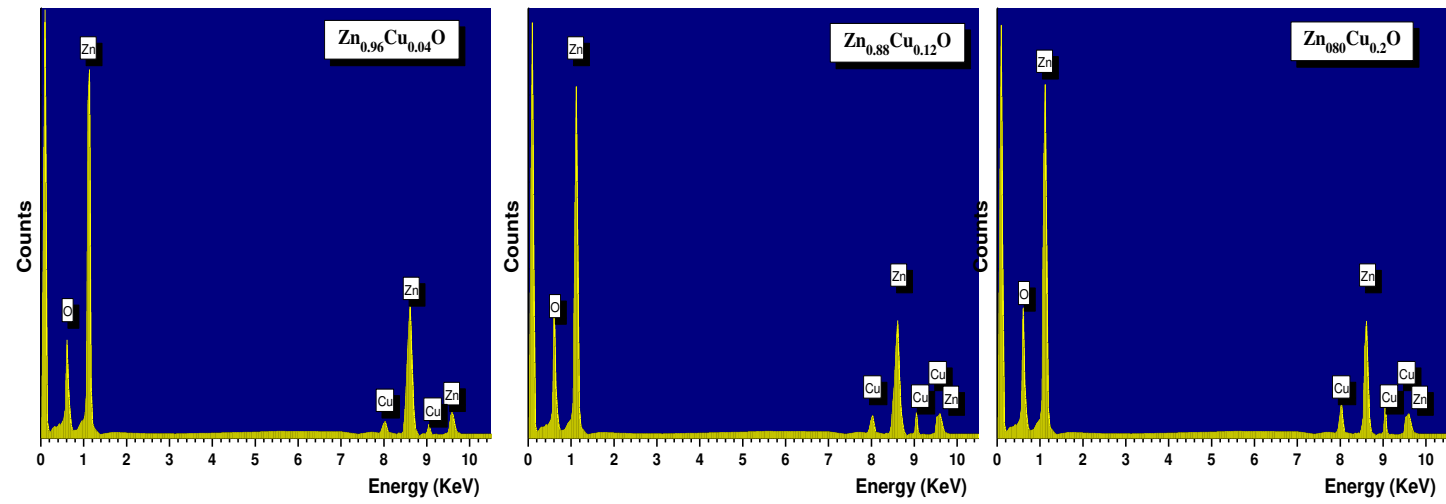

Fig.1. EDXS analysis of the $\mathrm{Cu}(0.04,0.12$, and 0.20) doped $\mathrm{ZnO}$ film.

\subsection{Structural and microstructure characterizations}

Fig. 2(a) shows the XRD spectra of undoped and $\mathrm{Cu}$ doped $\mathrm{ZnO}(\mathrm{ZnO}: \mathrm{Cu})$ thin films deposited by electron beam evaporation method at room temperature on glass substrate with different $\mathrm{Cu}$ concentrations of 2, 4, 8, 12, 16 and 20 at.\%. The results reveal that all films have a polycrystalline like structure with three reflection lines belonging to (100), (002) and (101) diffraction planes of the hexagonal wurtzite type structure suggested the existence of the $\mathrm{ZnO}$ structure; see (JCPDS No. 79-0205). In addition, the XRD pattern reveals a preferred oriented grain growth toward (002) plane due to the challenge between energy of surface and strain energy [36]. 

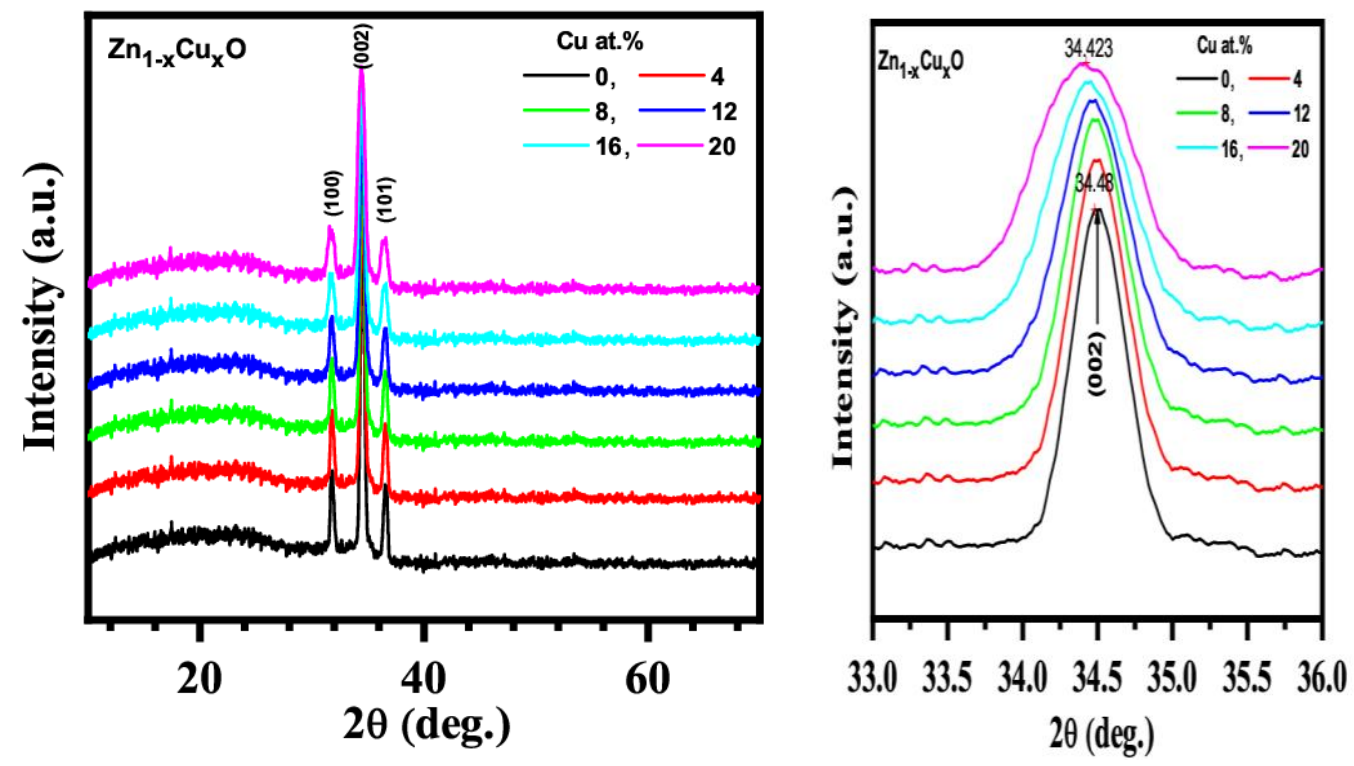

Fig. 2 (a) XRD spectra of $\mathrm{Cu}$ doped $\mathrm{ZnO}$ thin films with different $\mathrm{Cu} 0,2,4,8,12,16$ and 20 at. \%. , (b) The enlargement of the main diffraction peak (002) of $\mathrm{Cu}$-doped $\mathrm{ZnO}$ film.

It is worth noting that, the XRD spectra did not show any foreign peak related to copper phases such as copper oxide and or copper cluster, indicating a successful inclusion of $\mathrm{Cu}^{2+}$ ions into the $\mathrm{ZnO}$ lattice without change of the structure of $\mathrm{ZnO}$. It was found from Fig. 2(b) that the peak position of (002) plane is shifted towards lower diffraction angles (34.48-34.42 degree) due to the Strain introduced in the film by the partial replacement of $\mathrm{Cu}^{+2}$ ions by $\mathrm{Zn}^{+2}$ in the $\mathrm{ZnO}$ structure of semiconductor matrix with remarkable expansion in the cell volume. Fig. 3 shows the variations of the lattice parameters (a) and (c) with increasing of $\mathrm{Cu}$ incorporation into $\mathrm{ZnO}$ host lattice which are calculated from interspacing planner distance (d) and lattice indices (hkl) of the most predominantly preferred oriented peak by using the standard equation of using the standard relation of the hexagonal system: $\frac{1}{d_{h k l}^{2}}=\frac{4\left(h^{2}+h k+k^{2}\right)}{3 a^{2}}+\frac{l^{2}}{c^{2}}$. The results show that the lattice parameters increase with the increase of the $\mathrm{Cu}$ doping level which is attributed the incorporation of $\mathrm{Cu}^{2+}$ ions of larger ionic radius $(0.72 \AA)$ by $\mathrm{Zn}^{2+}$ ions of smaller ionic radius $(0.74 \AA)$, see Figs 3,4 . As can be seen the obtained lattice parameters (a), (c) and lattice volume values of undoped $\mathrm{ZnO}$ 
are consistent with the standard reported value of $\mathrm{ZnO}$ hexagonal structure, see JCPDS No. 79-0205. This behavior was given in literature for $\mathrm{ZnO}$ doped $\mathrm{Mn}$ [37] and $\mathrm{ZnO}$ doped $\mathrm{Cu}$ thin films [38]. In addition, the nanostructure nature of the films is examined by using DebyeScherrer's equations from the calculations of the mean crystallite sizes, $D=\frac{k^{\prime} \lambda}{\beta \cos \theta}$ and lattice microstrain, $\varepsilon=\frac{\beta}{4 \tan \theta}$ where, $\theta, \beta, k^{\prime}$ and $\lambda$ are the Bragg angle of most preferred oriented peak, radian FWHM, shape factor $(\approx 0.9)$ and the wavelength of the $\mathrm{CuK}_{\alpha}$ radiation, respectively. The value of the average crystallite size of the $\mathrm{Cu}$ doped $\mathrm{ZnO}$ film is found to decrease from $16.42 \mathrm{~nm}$ for $\mathrm{ZnO}$ to $12.28 \mathrm{~nm}$ for $\mathrm{Cu}: 20$ at. $\%$, confirming the nanostructure characteristic of the film.

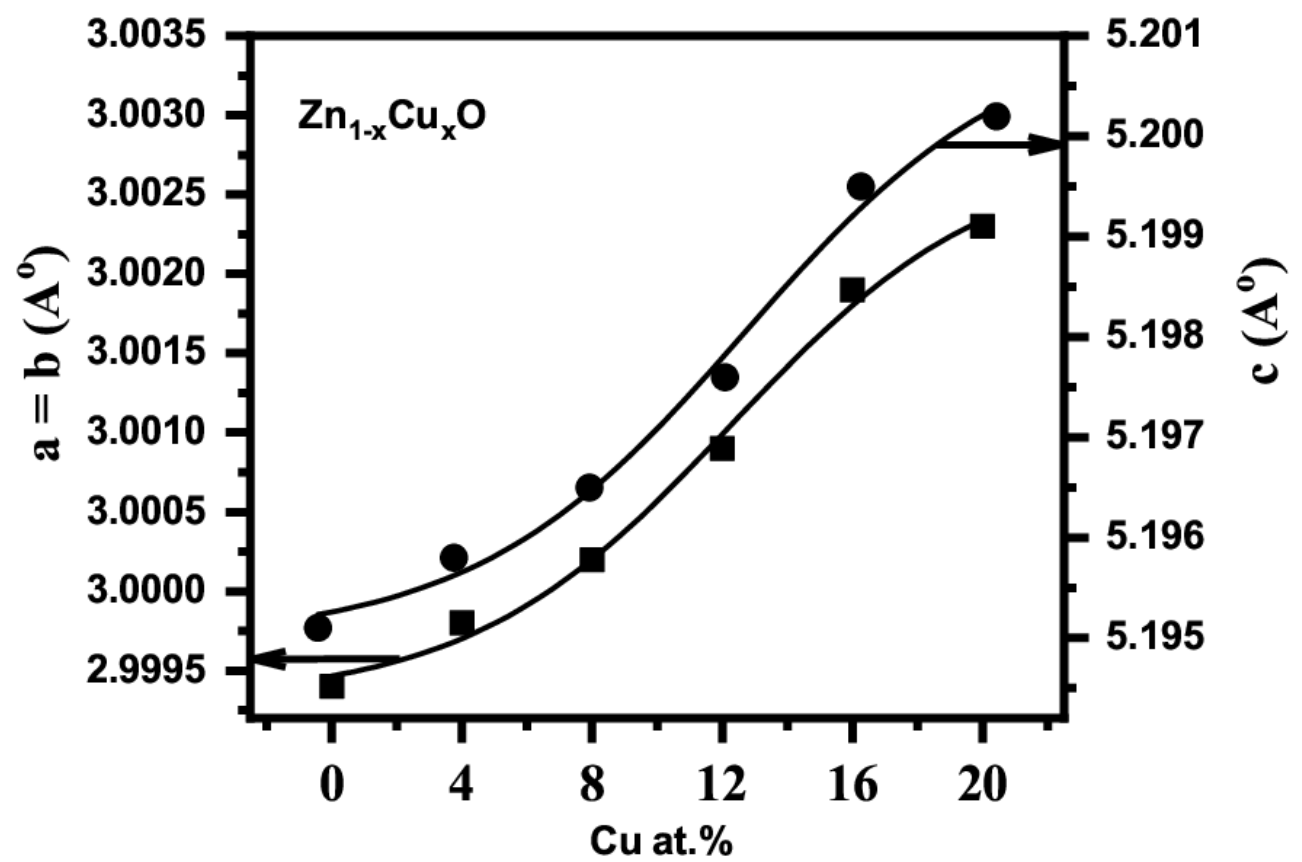

Fig. 3: The change of the lattice constant $\mathrm{a}(\AA)$ and $\mathrm{c}(\AA)$ in $\mathrm{ZnO}$ matrix with $\mathrm{Cu}$ content $(0.0$, $0.04,0.08,0.12,0.16,0.2)$

Fig. 5 displays the dependence of the microstructure parameters with $\mathrm{Cu}$ doping, see also Table 1. It can be seen that as the $\mathrm{Cu}$ doping increases, the average crystallite size decreases, while the micro strain increases. This indicates that the $\mathrm{Cu}$ substitution slows down the 
growth of $\mathrm{ZnO}$ grains [39]. As shown in Figure 5, the introducing of $\mathrm{Cu}$ ions into the $\mathrm{ZnO}$ matrix will cause the grain size to decrease, which is correlated to the inhibition of the nucleation growth mechanism (bad crystallinity), leading to lattice distortion [40], thereby degradation of crystallinity. This means that there is tensile micro strain embedded in the $\mathrm{ZnO}$ lattice. These practical observations are in accordance with the reported results of $\mathrm{Mn}$ doped $\mathrm{SnO}_{2}$ [41], Ni-doped $\mathrm{SnO}_{2}$ [42], $\mathrm{Mn}$ doped $\mathrm{ZnO}$ [43].

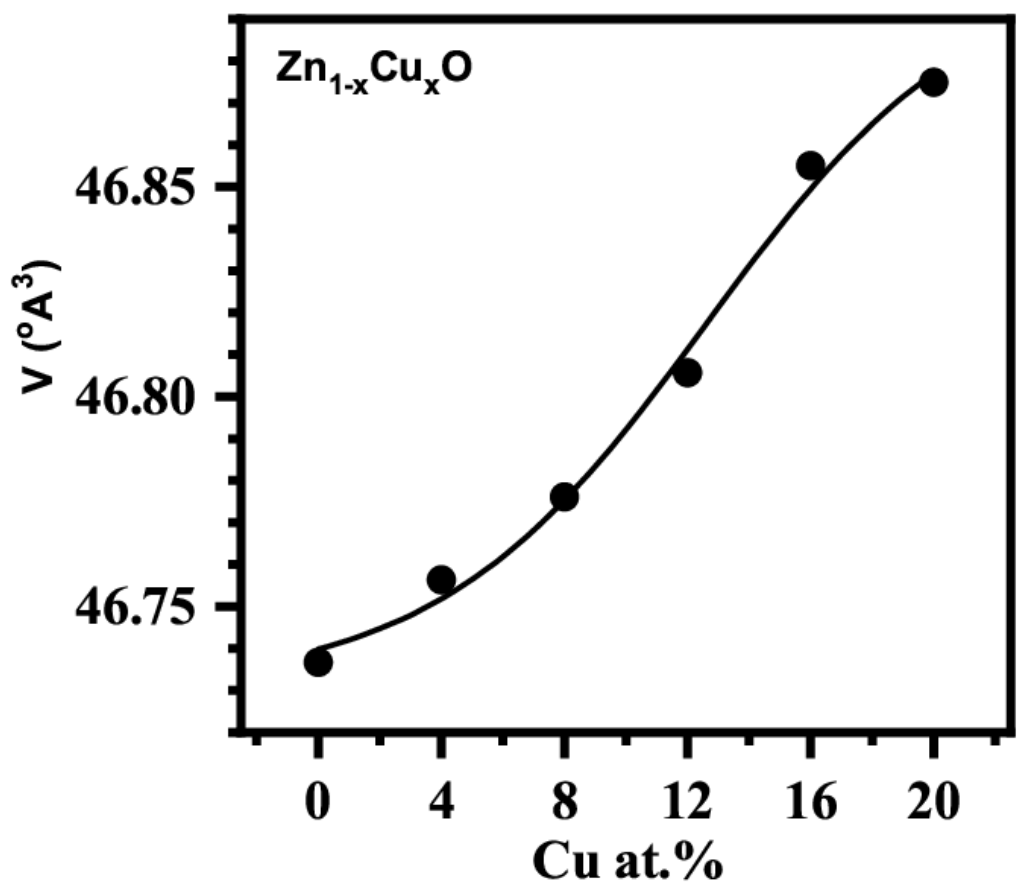

Fig. 4 The change of unit cell volume in $\mathrm{ZnO}$ matrix with $\mathrm{Cu}$ content $(0.0,0.04,0.08,0.12$, 0.16 , and 0.20$)$. 


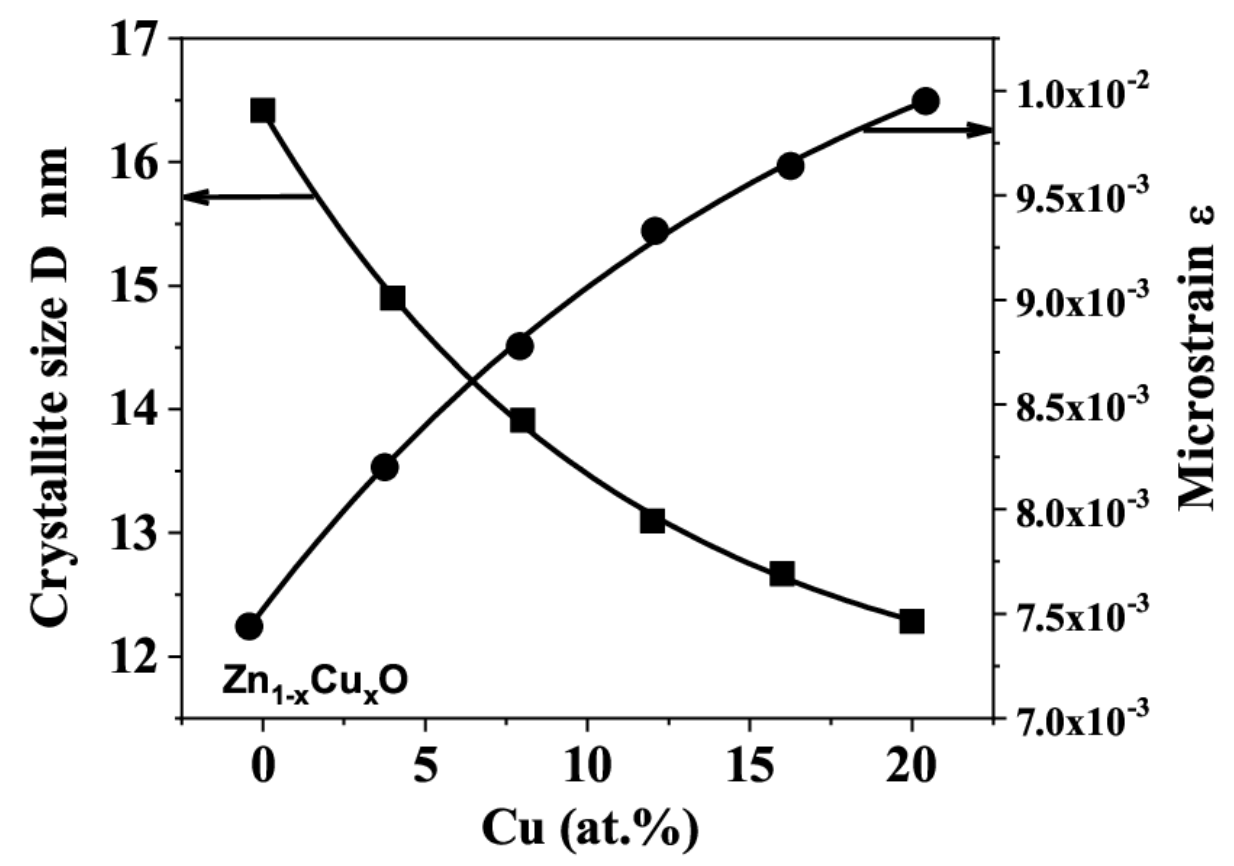

Fig.5 The change of the crystallite size $\mathrm{D}$ lattice strain $\varepsilon$ in $\mathrm{ZnO}$ matrix with various $\mathrm{Cu}$ contents $(0,4,8,12,16,20$ at. $\%)$.

\subsection{Surface morphology analysis}

The microscopic description of the surface morphology of the undoped and $\mathrm{Cu}$ doped $\mathrm{ZnO}$ films has been performed using AFM investigation. Fig. 6 shows the three dimensional (3D) AFM images of $\mathrm{ZnO}, \mathrm{ZnO}: 8$ at. $\%$ and $\mathrm{ZnO}: 16$ at. $\%$ films. The images show that the surface of the films has a highly densely spherical elongated packing grain with uniform arrangement. The observed regular distribution of the elongated spherical grains with similar directions confirms the observed preferred oriented grain growth toward (002) plane. The micrographs of the $\mathrm{ZnO}$ and $\mathrm{Cu}$ doped films were analyzed in details in order to identify the microscopic surface morphology parameters, such as the grain size, surface roughness and root mean square (RMS) surface roughness. The data extracted from the images analysis show that the grain size decreases from $24.4 \mathrm{~nm}$ to $18.6 \mathrm{~nm}$ with the increase of the $\mathrm{Cu}$ concentration from 0 at. $\%$ to 20 at.\% into $\mathrm{ZnO}$ lattice matrix, see our previously reported research [44, 45]. Furthermore, it was found that the surface roughness and RMS surface roughness are decreased from $4.01 \mathrm{~nm}$ to $3.4 \mathrm{~nm}$ and from $3.8 \mathrm{~nm}$ to $3.2 \mathrm{~nm}$, respectively 
with the increase of the $\mathrm{Cu}$ concentration from 0 at. $\%$ to 20 at. $\%$. The reduction in the surface roughness with the increase of $\mathrm{Cu}$ doping into $\mathrm{ZnO}$ films [38] and $\mathrm{CuTe}$ films [46] is reported in literature. It has to be mentioning that the grain size obtained from AFM is higher than the crystallite size calculated by XRD. This inconsistency can be ascribed to the fact that the crystallite size is a record of the size coherent scattering domain, whilst the grain size is a set of this coherently scattering domain separated by grain boundary. Besides, crystallite size reveals two distinct ranges when dislocations are located in the composition, while the difference between them is not visible in the AFM micrographs [42].
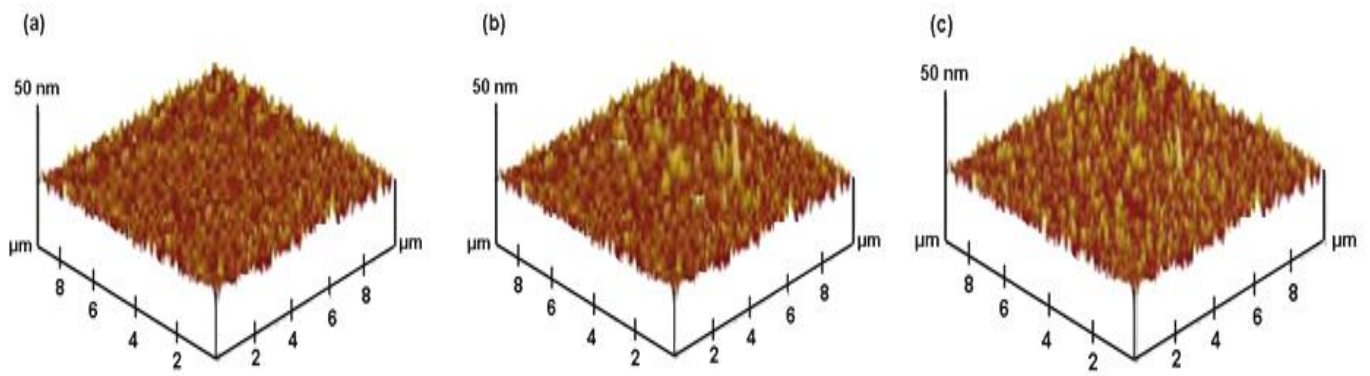

Fig. 6 3D-AFM images of (a) $\mathrm{ZnO}\left(\mathrm{x}=0\right.$ ) film (b) $\mathrm{Zn}_{0.92} \mathrm{Cu}_{0.08} \mathrm{O}$ and $\mathrm{Zn}_{0.84} \mathrm{Cu}_{0.16} \mathrm{O}$ film.

\subsection{Spectroscopic ellipsometric investigation of nanostructured $\mathrm{Zn}_{1-x} \mathrm{Cu} u_{x} \mathrm{O}$ thin films}

\subsubsection{SE spectrum of $\mathrm{Zn}_{1-x} \mathrm{Cu} u_{x} \mathrm{O}$ thin film}

SE technique requires a polarized light beam to interact with the thin film surface at a specific incidence angle. Therefore, SE is considered as a non-contact optical technique that characterizes the optical properties of the surface on which the polarized light beam is reflected. After reflecting from the surface of the film sample, the state of polarization of the incident polarized beam will change. SE technique is to measure the change in the intensity and polarization state of the polarized beam when reflected from the film surface. The beauty of SE technique is that it can correlate the optical properties of the reflective surface with the variation in the intensity and polarization state of the polarized beam reflected from the film surface. In SE, the experimentally measured factors are the amplitude ratio $\left(\psi_{\operatorname{Exp}}\right)$ and the 
phase difference $\left(\Delta_{\text {Exp }}\right)$ between incident and reflected polarized light waves. Using some fitting analysis, the optical constants (n\&k) of the studied film can be obtained from the experimentally ellipsometric factors $\psi_{\text {Exp. }}$ and $\Delta_{\text {Exp. }}$ The spectral change of the SE factors are directly interrelated to the coefficient of amplitude reflection via the given relationship [47, 48, 49]:

$$
\rho=\frac{r_{p}}{r_{s}}=\tan \psi \exp (i \Delta)
$$

The terms $r_{p}$ and $r_{s}$ shown in relation 1 are the Fresnel coefficients of light waves polarized parallel to and vertical to the plane of incidence, respectively, and $\Delta$ is difference in phase between the parallel and the vertical component of the polarized wave. Spectra of $\psi_{\text {Exp }}$ and $\Delta_{\text {Exp. }}$ of the $\mathrm{Zn}_{1-\mathrm{x}} \mathrm{Cu}_{\mathrm{x}} \mathrm{O}$ film with different $\mathrm{Cu}$ contents measured when the incident angle is equal to $70^{\circ}$ is depicted in Fig 7(a,b). In the 600-1100 nm spectral range, the $\psi_{\text {Exp. }}$ spectra show obvious oscillations. This oscillation occurs due to the overlapping between light waves reflected from the top surface and the light waves go during the film. The spectral oscillation observed in the $\psi_{\text {Exp. }}$ spectrum indicates that the film under investigation is transparent. Near to the energy band gap of the studied film (250-590nm), the oscillation disappears, indicating that the absorption process has begun. A theoretical optical model was proposed in order to extract the physical properties of the studied film (surface irregularities, optical parameters (n $\& \mathrm{k})$ and film thickness $)$ from the $\psi_{\text {Exp. }}$ and $\Delta_{\text {Exp. }}$ spectra, see Fig. $7(\mathrm{a}, \mathrm{b})$. Regarding the physical properties, the proposed model must match the actual structure of the studied film. Using the proposed optimization simulation program of the optical model of fitting parameters that matches the actual sample structure, the $\mathrm{n}$ and $\mathrm{k}$ of the studied film can 


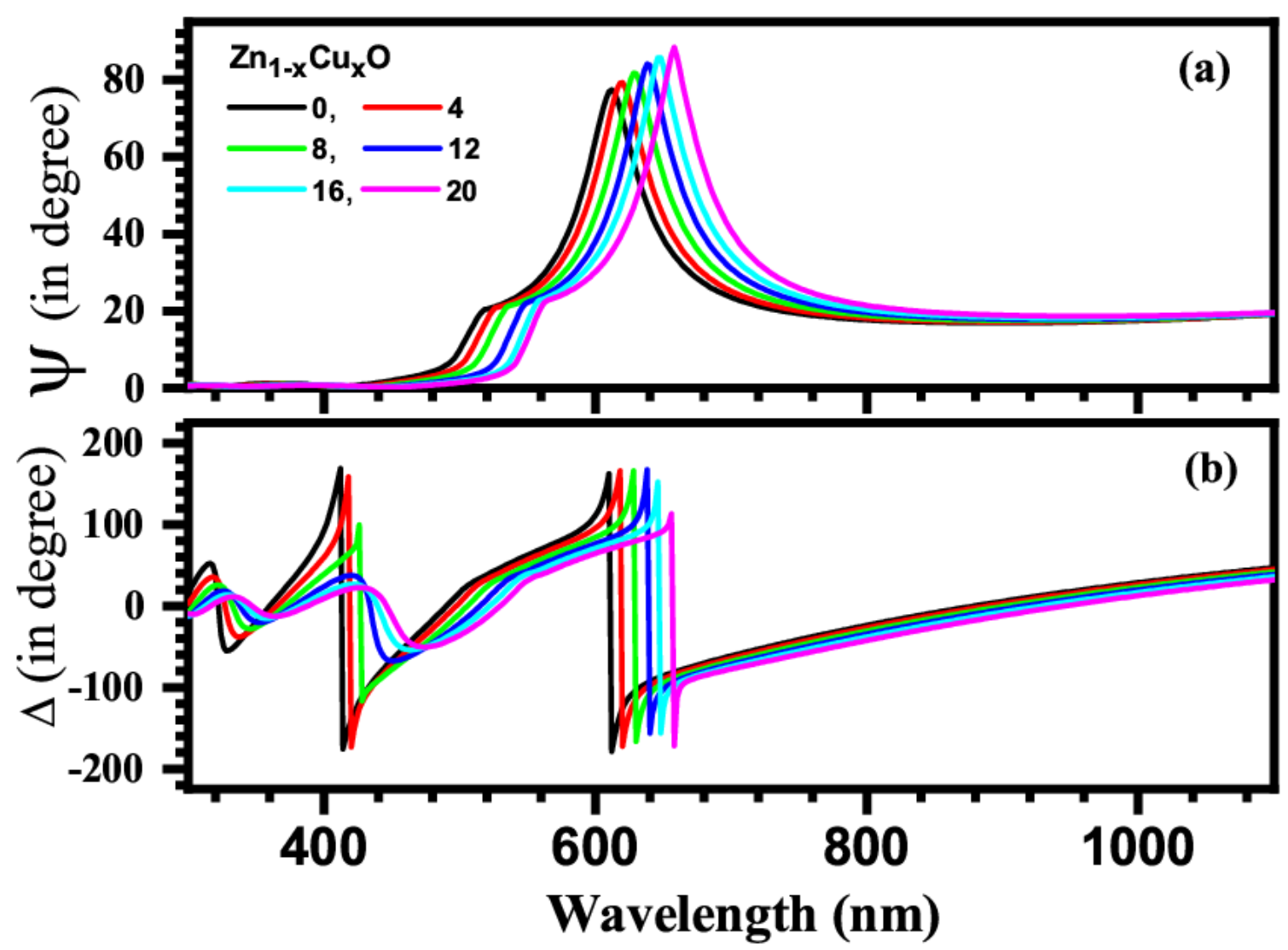

Fig.7 (a,b). For different $\mathrm{Cu}$ concentration $(\mathrm{x}=0.0,0.04,0.08,0.12,0.16,0.2) \mathrm{ZnO}$ film, the spectral characteristics of the SE parameters $\Psi$ and $\Delta$ with wavelength is measured at the incident angle $\theta=70^{\circ}$

be obtained from the matching of the experimental and simulated SE spectra of $\psi_{\text {Exp., }} \Delta_{\text {Exp. }}$, $\psi_{\text {Cal. }}$ and $\Delta_{\text {Cal. }}$, respectively. By reducing the mean square error function (MSE) calculated using Levenberg-Marquardt mathematical relation, the equivalent between the measured SE parameters $\psi_{\text {Exp., }} \Delta_{\text {Exp. }}$ and the calculated SE parameters $\psi_{\text {Cal. }}, \Delta_{\text {Cal. }}$ can be obtained. The mathematical relation of Levenberg-Marquardtis [44, 45, 50]:

$\mathrm{MSE}=\frac{1}{2 N-M} \sum_{i=1}^{N}\left(\left(\frac{\psi_{i}^{\text {mod }}-\psi_{i}^{\exp }}{\sigma_{\psi, i}^{\exp }}\right)^{2}+\left(\frac{\Delta_{i}^{\text {mod }}-\Delta_{i}^{\exp }}{\sigma_{\Delta, i}^{\exp }}\right)^{2}\right)$

The factors given in Eq. 2 is; $N$ is the number of measurement data pairs of $\psi(\lambda)$ and $\Delta(\lambda)$ included in the fittingprocess, $\mathrm{M}$ is the fitting parameters number, and $\mathrm{i}$ is an running discrete index of the sum. In addition, $\psi_{\mathrm{i}}^{\exp }, \Delta_{\mathrm{i}}^{\exp }$ and $\psi_{\mathrm{i}}^{\bmod }, \Delta_{\mathrm{i}}^{\bmod }$ are the measured and simulated 
values of the SE parameters, respectively. During the average period of the rotating polarizer and the analyzer, the SE parameter standard deviation computed from the error bar of the determined calibration parameter and the irregularity of the determined data are given by $\left(\sigma_{\psi, \mathrm{i}}^{\mathrm{exp}}\right.$ and $\left.\sigma_{\Delta, \mathrm{i}}^{\mathrm{exp}}\right)$. Soon, we reached a good agreement between the calculated results of the

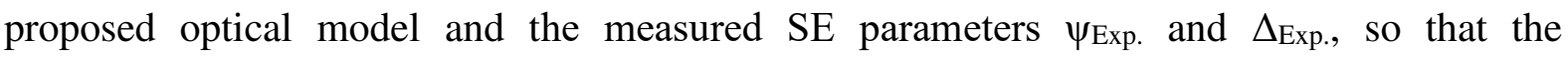
wavelength dependence of the optical constants of the studied film can be determined. In the following paragraphs, we will give more detailed discussion of the optical model developed for SE data analysis of $\mathrm{Zn}_{1-\mathrm{x}} \mathrm{Cu}_{\mathrm{x}} \mathrm{O}$ thin films [51, 52 53].

\subsubsection{Optical Model}

The response of the film to the externally incident polarized photon field can be fully explained by its complex dielectric relation $\left(\varepsilon(E)=\varepsilon_{1}+i \varepsilon_{2}\right)$ from which the optical behavior of the thin film material can be obtained. Building an appropriate optical model and using nonlinear fitting procedure, microstructure parameters such as film surface irregularity, thickness and nonuniformity of film thickness can be extracted from $\psi_{\text {Exp. }}$ and $\Delta_{\text {Exp. }}$ The proposed optical model used to simulate the measured SE parameters $\psi_{\text {Exp. }}$ and $\Delta_{\text {Exp }}$ of the $\mathrm{Zn}_{1-\mathrm{x}} \mathrm{Cu}_{\mathrm{x}} \mathrm{O}(0.0 \leq \mathrm{x} \leq 0.20)$ thin film is depicted in Fig.8. The optical model consists of threelayer structure. These layers are: silica glass substrate, thin film layer of $\mathrm{Zn}_{1-\mathrm{x}} \mathrm{Cu}_{\mathrm{x}} \mathrm{O}$ $(0.0 \leq x \leq 0.1)$ and surface roughness layer. The Cauchy dispersion relation is used to fully predict the optical response of the substrate. In our measurement, the optical constants of the silica substrate can be easily extracted from applying fitting procedure offered by software obtained from J. A. Woollam Company [Error! Bookmark not defined.]. The substrate optical parameters extracted from the ready use Woollam software are very consistent with the values reported in the Hand book of optics [54]. Thin film layer of $\mathrm{Zn}_{1-\mathrm{x}} \mathrm{Cu} \mathrm{u}_{\mathrm{x}} \mathrm{O}$ $(0.0 \leq x \leq 0.20)$ is modeled as a gradient index layer. In gradient index scheme the fulllayer thickness is separated into several sub-layers with small thicknesses inside, and the optical 
characteristics of each sub-layer are marginally dissimilar from those of the nearby layers. The B-spline calculation scheme is used to really examine the spectral performance of each layers composing the actual film thickness of the nanocrystalline $\mathrm{Zn}_{1-\mathrm{x}} \mathrm{Cu}_{\mathrm{x}} \mathrm{O}(0.0 \leq \mathrm{x} \leq 0.2)$ layers. Since our film is composed of three materials $\mathrm{Sn}, \mathrm{Cr}$ and $\mathrm{O}$, therefore, effective medium approximation (EMA) is included in the gradient index scheme to account for the existence of more than one material composing the film structure. Bruggeman EMA model is included in SE analysis through the following relation [55]:

$$
\sum_{i=1}^{m} f_{i} \frac{\varepsilon_{i}-\varepsilon_{e f f}}{\varepsilon_{i}+2 \varepsilon_{e f f}}=0 \quad \sum_{i=1}^{m} f_{i}=1
$$

In Eq.3, $\mathrm{m}=3$ denotes the number of component materials that make up the film, the effective dielectric function is denoted by $\varepsilon_{\text {eff }}$, and also the volume fraction and complex dielectric function of component $\mathrm{i}$ are expressed by $\mathrm{f}_{\mathrm{i}}$ and $\varepsilon_{\mathrm{i}}$, respectively. Eq. 3 is applied under the assumption of isotropy and the topological equivalence of each component; these limitations can be improved by using the general EMAs model [56]. In addition, for the sake of simplicity, it is supposed that the surface irregularity layer depicted in Fig. 10 varies as periodic function of the $\mathrm{Zn}_{1-\mathrm{x}} \mathrm{Cu}_{\mathrm{x}} \mathrm{O}(0.0 \leq \mathrm{x} \leq 0.1)$ oxide film and air. The SE parameters ( $\psi$ Exp. and $\Delta_{\text {Exp. }}$ ) demonstrated in the Figs.9-10, (black squares and blue dots) and the calculated data $\left(\psi_{\text {cal. }}\right.$ and $\left.\Delta_{\text {cal. }}\right)$ shown as black and blue lines are presented. As clearly depicted in Figs. 9-10, nice coincident between the measured SE parameters $\left(\psi_{\text {Exp. }}, \Delta_{\text {Exp. }}\right)$ and the calculated SE parameters $\left(\psi_{\text {cal., }}, \Delta_{\text {cal. }}\right)$ in the entire recorded wavelength regime is achieved. The MSE values generated by the harmony between measured and calculation SE parameters are 1.12 and 1.11 for $\mathrm{ZnO}$ and $\mathrm{Zn}_{0.84} \mathrm{Co}_{0.16} \mathrm{O}$, respectively. In addition, the fitting activity also produce approximate value for the thickness of the film and surface irregularity which are $214 \pm 0.44 \mathrm{~nm}, 3.90 \mathrm{~nm}, 211 \pm 0.41 \mathrm{~nm}$ and $3.60 \mathrm{~nm}$ for $\mathrm{ZnO}$ and $\mathrm{Zn}_{0.84} \mathrm{Co}_{0.16} \mathrm{O}$, respectively. As 
we have noticed, the surface irregularity extracted from the SE fitting scheme is in very good coincidence with the value obtained from the AFM measurement reported earlier in the morphology investigation section.

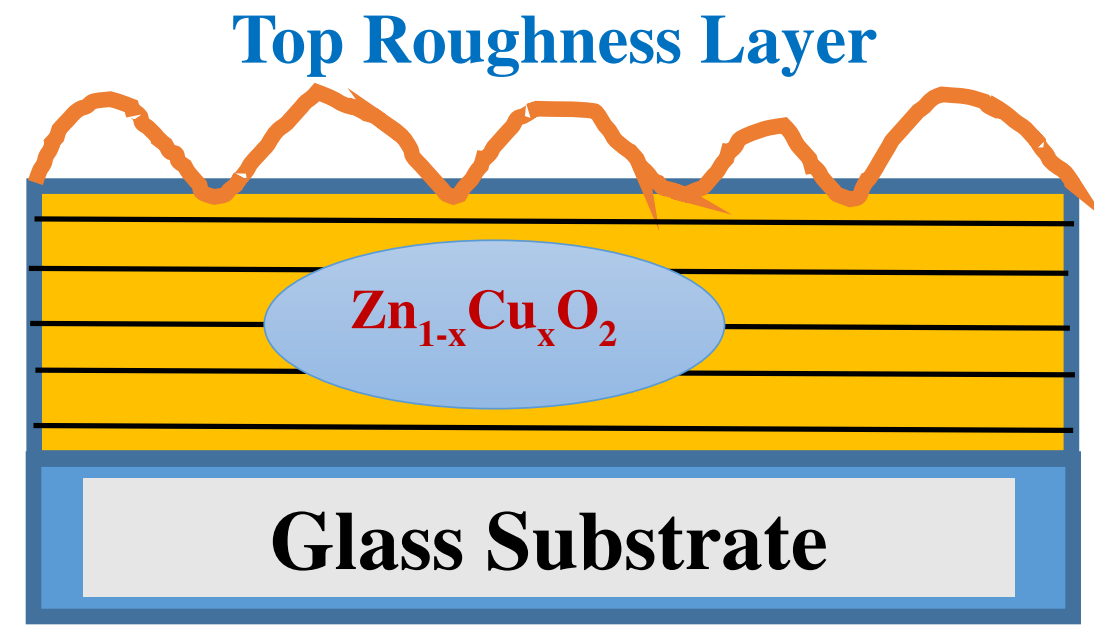

Fig.9. An optical model constructed for describing measured SE spectrum of $\mathrm{Zn}_{1-\mathrm{x}} \mathrm{Cu}_{\mathrm{x}} \mathrm{O}$ thin film settle on silica substrate.

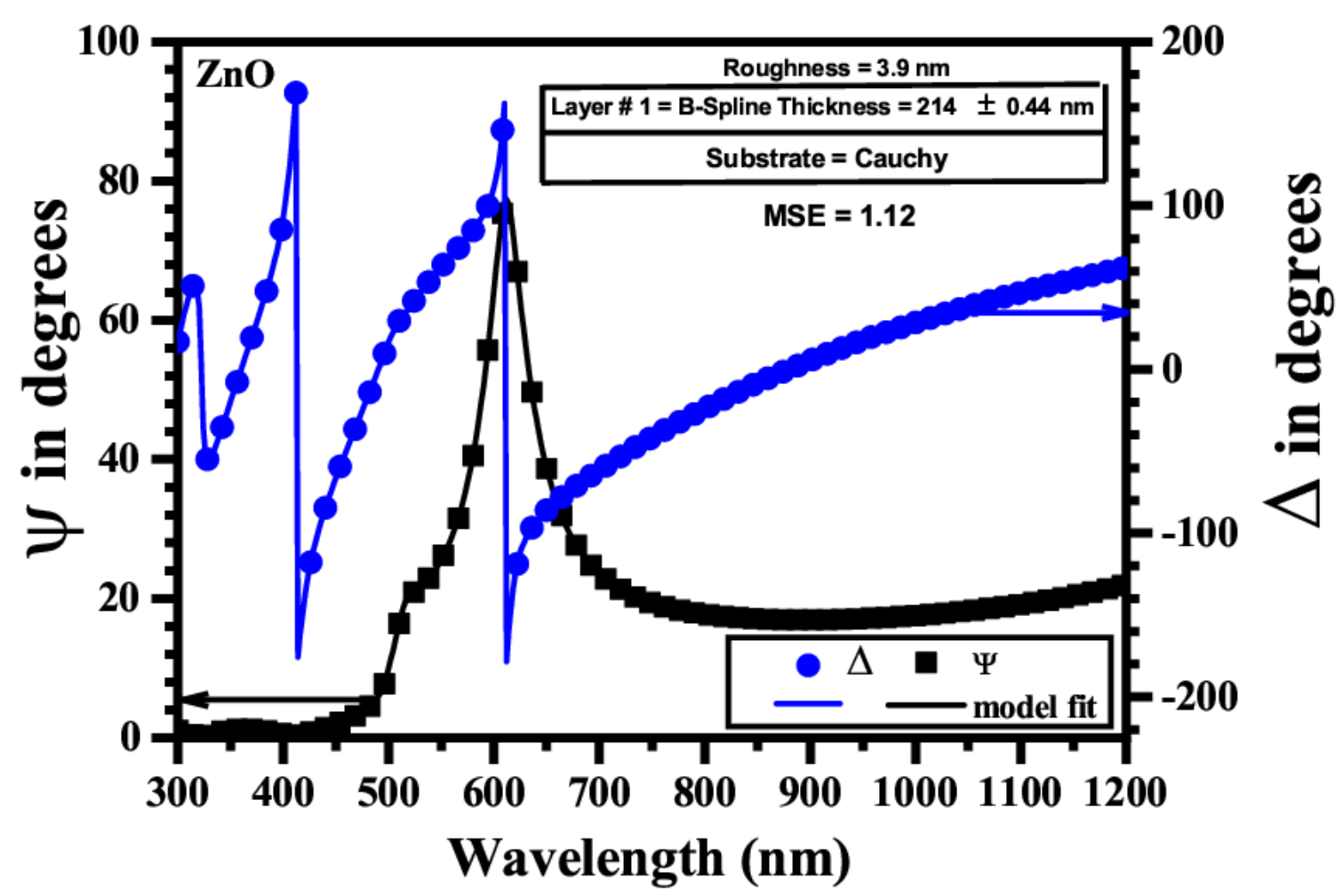

Fig.9 the $\psi$ and $\Delta$ spectra obtained by the SE measurements (black square and blue dots) of the $\mathrm{ZnO}$ sample at an incident angle of $70^{\circ}$. The solid line of different colors represents the calculated data (fitted) produced by the three-layer model. 


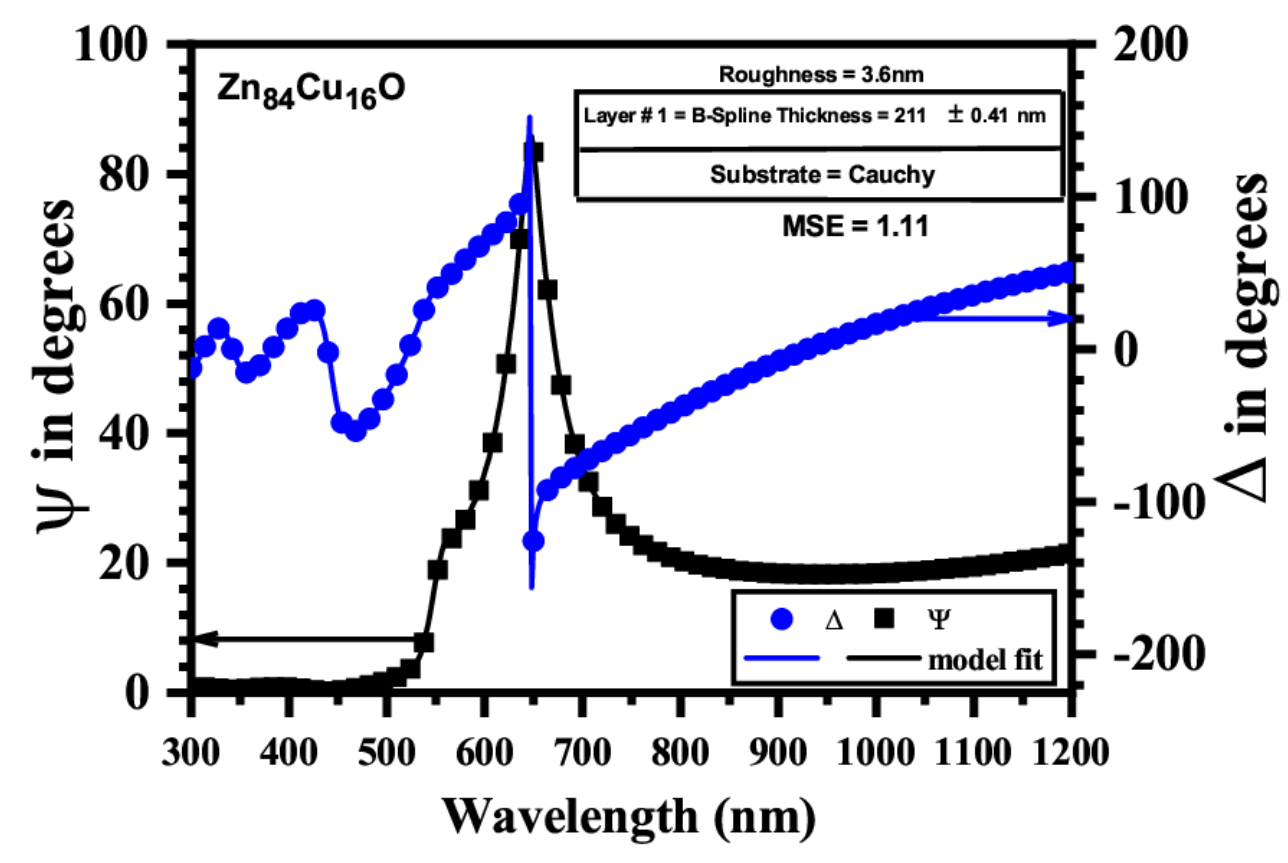

Fig.10 The $\psi$ and $\Delta$ spectra obtained by the SE measurements (black square and blue dots) of the $\mathrm{Zn}_{0.84} \mathrm{Cu}_{0.16} \mathrm{O}$ sample at an incident angle of $70^{\circ}$. The solid line of different colors represents calculated data (fitted) produced by the three-layer model.

\subsubsection{Absorption process occurs in nanocrystalline Zn1-xCuxOthin film}

This section is much concerned with the optical properties of nanocrystalline $\mathrm{Zn}_{1}$ ${ }_{\mathrm{x}} \mathrm{Cu}_{\mathrm{x}} \mathrm{O}$ films extracted from the previously developed optical model. First, the absorption occurs in the $\mathrm{Zn}_{1-\mathrm{x}} \mathrm{Cu}_{\mathrm{x}} \mathrm{O}$ nanocrystalline film is considered, and, the spectral dependence of the refractive index of the $\mathrm{Zn}_{1-\mathrm{x}} \mathrm{Cu}_{\mathrm{x}} \mathrm{O}$ nanocrystalline film is examined later. The complex permittivity $\left(\xi(\lambda)=\varepsilon_{1}(\lambda)+i \varepsilon_{2}(\lambda)\right)$ of the $\mathrm{Zn}_{1-\mathrm{x}} \mathrm{Cu}_{\mathrm{x}} \mathrm{O}$ nanocrystalline film is obtained as a direct consequence of the coincidence between measured SE factors ( $\left.\psi_{\text {Exp. }}, \Delta_{\text {Exp. }}\right)$ and the calculated SE factors $\left(\psi_{\text {cal. }}, \Delta_{\text {cal. }}\right)$. The optical factors $(\mathrm{n} \& \mathrm{k})$ of the studied films are correlated to the value of $\varepsilon_{1}(\lambda)$ and $\varepsilon_{2}(\lambda)$ through the mathematical formula:

$\varepsilon_{1}(\lambda)=\mathrm{n}^{2}-\mathrm{k}^{2} \quad \& \quad \varepsilon_{2}(\lambda)=2 \mathrm{nk}$

In the previous relationship (Eq.4), the factors $\mathrm{n}$ and $k$ are expressed as refractive index (real part) and extension coefficient (imaginary part) of the complex dielectric constant $\varepsilon(\lambda)$, 
respectively. Using the following relationship, the real and imaginary parts of $\varepsilon(\lambda)$ are interconnected to optical factors of film being studied using the formula [57]:

$n(\lambda)=\frac{1}{\sqrt{2}}\left[\varepsilon_{1}+\left(\varepsilon_{1}^{2}+\varepsilon_{2}^{2}\right)^{0.5}\right]^{0.5} \& \quad k(\lambda)=\frac{1}{\sqrt{2}}\left[-\varepsilon_{1}+\left(\varepsilon_{1}^{2}+\varepsilon_{2}^{2}\right)^{0.5}\right]^{0.5}$

The wavelength dependence of the absorption coefficient $\alpha(\lambda)$ occurring inside nanocrystalline $\mathrm{Zn}_{1-\mathrm{x}} \mathrm{Cu}_{\mathrm{x}} \mathrm{O}$ film is linked directly to the extension coefficient $\mathrm{k}(\lambda)$ via the formula:

$\mathrm{k}(\lambda)=\frac{\alpha(\lambda) \lambda}{4 \pi}$

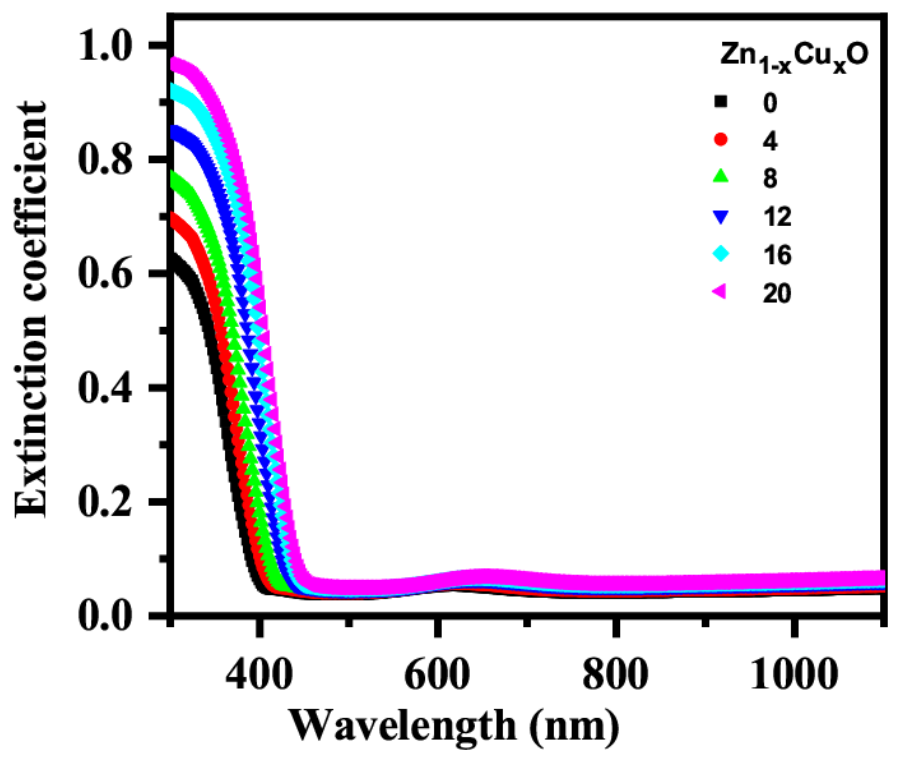

Fig.11 The extinction coefficient of $\mathrm{Cu}$ doped $\mathrm{ZnO}$ thin film versus wavelength with different $\mathrm{Cu}$ concentrations $0,2,4,8,12,16$ and 20 at. $\%$. 


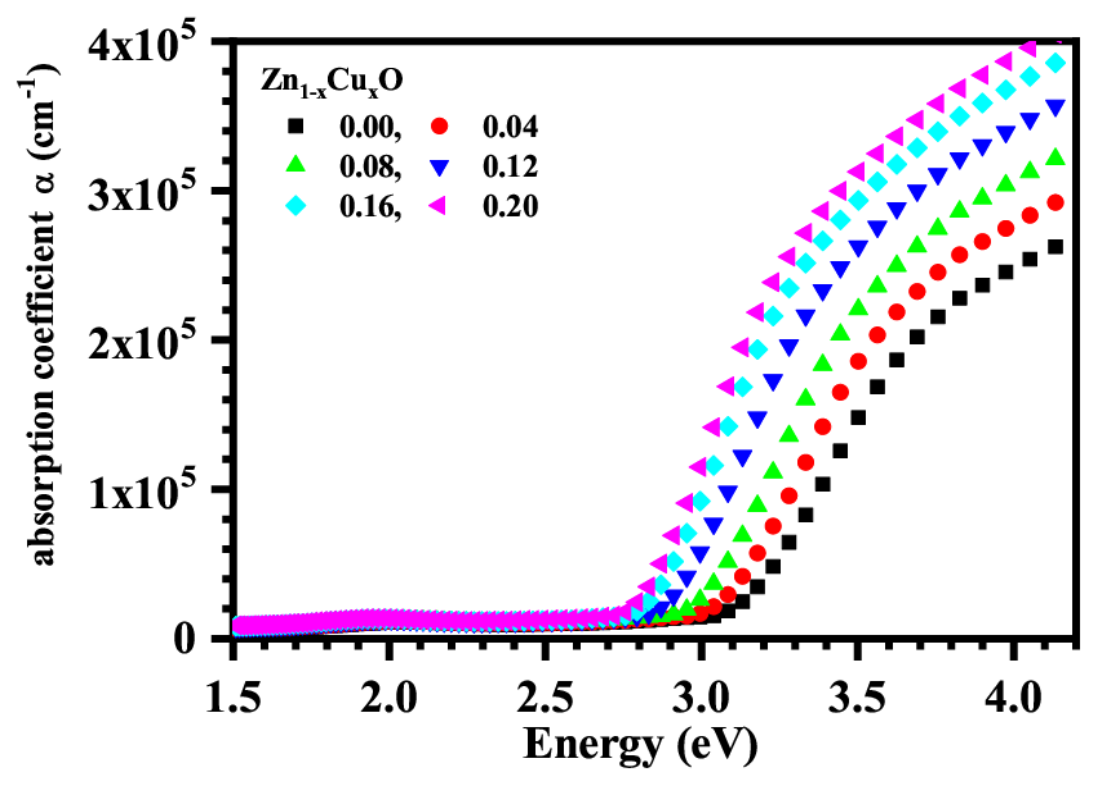

Fig.12. The absorption coefficient of $\mathrm{Cu}$ doped $\mathrm{ZnO}$ thin film samples with different $\mathrm{Cu}$ concentrations varies with photon energy extracted from SE measurements.

As shown in Figure 11, the spectral dependence of the parameter $k(\lambda)$ of nanocrystalline $\mathrm{Zn}_{1-}$ ${ }_{x} \mathrm{Cu}_{x} \mathrm{O}$ films with different $\mathrm{Cr}$ contents is calculated through the relationship $\mathrm{k}(\lambda)=\alpha(\lambda) \lambda / 4 \pi$. The results presented in Fig.11 show that at shorter wavelength below $350 \mathrm{~nm}$ the value of $\mathrm{k}$ rises with increasing of $\mathrm{Cu}$ dopant. Since the energy of the propagated photons is quite close to the energy band gap of the investigated $\mathrm{Zn}_{1-\mathrm{x}} \mathrm{Cu}_{\mathrm{x}} \mathrm{O}$ film, this behavior can be expected. Once we have the dispersion of the extinction coefficient $k(\lambda)$ then we can easily calculate the parameter $\alpha(\mathrm{E})$. Figure 12 illustrates the dependence of the absorption coefficient $\alpha(\mathrm{E})$ of the $\mathrm{Zn}_{1-\mathrm{x}} \mathrm{Cu}_{\mathrm{x}} \mathrm{O}$ film with different $\mathrm{Cu}$ doping on the photon energy. Obviously, the onset of absorption processes close to and above the energy gap $\mathrm{E}_{\mathrm{g}} \approx 2.7 \mathrm{eV}-4.2 \mathrm{eV}$ is clearly observed, therefore, as expected the absorption coefficient $\alpha(\mathrm{E})$ rises up with the increment of the $\mathrm{Cu}$ level. In contrast, the absorption coefficient becomes almost flat (region of transparency) below $1.5 \mathrm{eV}$ up to $2.6 \mathrm{eV}$. The apparent rapid decline of the absorption curve with decreasing photon energy is basically attributed to the absorption, in which electrons transition through 
the energy gap to reach conduction band of the studied film. Using the well-known Tauc relationship, the optical energy gap $\mathrm{E}_{\mathrm{g}}$ can be extracted using the following relationship [58]:

$$
\alpha h v=\alpha_{0}\left(h v-E_{g}\right)^{n}
$$

In the previous equation (Eq.8), the parameter $\mathrm{n}$ refers to the index indicating the type of optical transition process and $\alpha_{0}$ is constant. When $n=1 / 2$ the optical transition referred to the allowed direct energy inter-band. According to Eq.8, $\mathrm{E}_{\mathrm{g}}$ is derived by identifying the intersection of the linear portion of the extrapolation of $(\alpha h v)^{2}$ with respect to $(h v)$ at $(\alpha h v)^{2}=$ 0 . The direct band gap of the $\mathrm{Zn}_{1-\mathrm{x}} \mathrm{Cu}_{\mathrm{x}} \mathrm{O}(0.0 \leq \mathrm{x} \leq 0.2)$ nanocrystalline film has been calculated based on the $(\alpha h v)^{2}$ vs. (hv) diagram. Fig. 13 indicates that as the $\mathrm{Cu}$ concentration increases from 0.0 up to 0.2 , the band gap of the film decreases from $3.286 \mathrm{eV}$ to $2.934 \mathrm{eV}$. Note, the values of the energy gap of the investigated film are in accord with those given in literature $\mathrm{ZnO}(3.29 \mathrm{eV})$ [59]. Based on atomic configuration of the chemical components constituting the film, the dependence of the energy gap of the $\mathrm{Zn}_{1-\mathrm{x}} \mathrm{Cu}_{\mathrm{x}} \mathrm{O}(0.0 \leq \mathrm{x} \leq 0.20)$ nanocrystalline film can be understood. Therefore, we will start with the valence electronic configurations of the chemical components that make up the film structure. The bare $\mathrm{ZnO}$ film has crystal structure of wurtzite $\mathrm{ZnO}$ which belongs to the hexagonal system with space group P63mc, and the symmetry $\mathrm{C} 46 \mathrm{v}$. In the crystal structure of $\mathrm{ZnO}$ each zinc ion is surrounded by four oxygen ions to form [ $\mathrm{ZnO} 4]$. The configuration of the valance electrons composing $\mathrm{Zn}_{1-}$ ${ }_{x} \mathrm{Cu}_{\mathrm{x}} \mathrm{O}$ are: $3 \mathrm{~d}^{10} 4 \mathrm{~s}^{2}, 3 \mathrm{~d}^{10} 4 \mathrm{~s}^{1}$ and $2 \mathrm{~s}^{2} 2 \mathrm{p}^{4}$ for $\mathrm{Zn}, \mathrm{Cu}$ and $\mathrm{O}$ atoms, respectively. According to the reported results of energy gap calculation and photoelectron emission spectroscopy, the hart of the valence band (VB) of $\mathrm{ZnO}$ is mostly composed of a mixture of $\mathrm{O} 2 \mathrm{~s}$ and $\mathrm{Cu} 3 \mathrm{~d}$ atomic orbitals, while the upper VB is mainly $\mathrm{O} 2 \mathrm{p}$ with some mixed states of $\mathrm{Cu} 4 \mathrm{~s}$, respectively $[60,61]$. In contrast, the bottom part of the conduction band $(\mathrm{CB})$ of $\mathrm{ZnO}$ is built from $4 \mathrm{~s}$ of $\mathrm{Zn}$ with strong contributions of $\mathrm{Zn} 3 \mathrm{~d}$, O 2s and $\mathrm{O} 2 \mathrm{p}$ states observed at higher energies [60]. As mentioned earlier, the interaction of different energy states of $\mathrm{Zn}$ and $\mathrm{O}$ 
atoms results in the formation of wurtzite $\mathrm{ZnO}$ of hexagonal crystal structure [61]. When the $\mathrm{Cu}^{+2}$ atom is introduced into $\mathrm{ZnO}$ matrix, it will replace the cation site $\mathrm{Zn}^{+2}$ of the $\mathrm{ZnO}$ structure. Since both $\mathrm{Zn}$ and $\mathrm{Cu}$ atoms own d-electrons, therefore, the intra-atomic interaction for the intensely related d-electrons will form so called $d$-d interactions. The partial replacement of $\mathrm{Zn}^{+2}$ by $\mathrm{Cu}^{+2}$ leads to the existence of d-state of $\mathrm{Cu}^{+2}$, which is energetically close to the $\mathrm{Zn}^{+2} \mathrm{~d}$ in $\mathrm{VB}$ of the $\mathrm{ZnO}$ matrix. The d-d interaction between $\mathrm{Cu}^{+2}$ and $\mathrm{Zn}^{+2}$ will result in the formation of a hybrid state close to the valence band of the $\mathrm{ZnO}$ crystal, which consequently will reduce the energy gap of $\mathrm{ZnO}[62]$. Our results show that as the doping level of $\mathrm{Cu}$ in $\mathrm{ZnO}$ semiconductor matrix $\left(\mathrm{Zn}_{1-\mathrm{x}} \mathrm{Cu}_{\mathrm{x}} \mathrm{O}(0.0 \leq \mathrm{x} \leq 0.2)\right)$ increases from $0 \%$ to 20 $\%$, the energy gap reduces from $3.29 \mathrm{eV}$ to $2.93 \mathrm{eV}$.

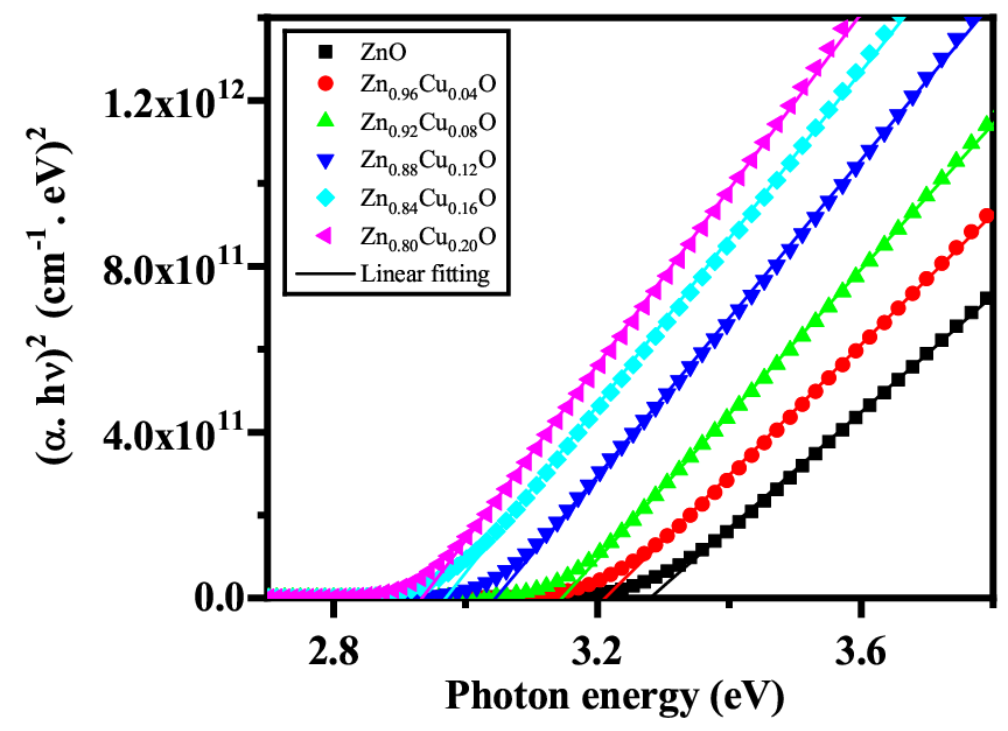

Fig.13. For nanocrystalline $\mathrm{Zn}_{1-\mathrm{x}} \mathrm{Cu}_{\mathrm{x}} \mathrm{O}$ films with different $\mathrm{Cu}$ contents the variation of $(\alpha \mathrm{h} v)^{2}$ as a function of photon energy $(\mathrm{h} v)$ is depicted.

\subsubsection{Refractive Index characteristics of $\mathrm{Zn}_{1-x} C u_{x} O$ thin film}

The refractive index of a thin film is one of the essential properties because it illustrates the interaction of photon waves propagating through the film with the material constitutes. Furthermore, it can also alter the properties of the propagating photon such as velocity of propagation (phase), optical pathway and its absorption. Technologically, the 
material refractive index represents the basic layout parameter of most optoelectronic and polarization optical devices. Consequently, this section aims to analyze the optical characteristics of the dispersion of refractive index of nanostrcutured $\mathrm{Zn}_{1-\mathrm{x}} \mathrm{Cu}_{\mathrm{x}} \mathrm{O}$ film. For nearly fixed film thickness, figure 15 displays the wavelength dependence of the refractive index of nanocrystalline $\mathrm{Zn}_{1-\mathrm{x}} \mathrm{Cu}_{\mathrm{x}} \mathrm{O}$ for different percentage of $\mathrm{Cu}(\mathrm{x}=0.0,0.04,0.08,0.12$, 0.16 and 0.2). As clearly depicted in Fig.15, the refractive index (shown as symbols of different colours) of the $\mathrm{Zn}_{1-\mathrm{x}} \mathrm{Cu}_{\mathrm{x}} \mathrm{O}$ nanocrystalline thin film enhances with increasing $\mathrm{Cu}$ level. The reason is that the refractive index of a substance is directly related to its polarizability through the Lorenz-Lorenz equation [63], where the polarizability of a material increases with the increase of the atomic radius of the atoms that make up the material. Therefore, replacing $\mathrm{Cu}$ with a larger atomic radius $(1.38 \AA$ ) with $\mathrm{Zn}$ with a smaller atomic radius $(1.28 \AA)$ can increase the polarizability and consequently increasing the refractive index. This behavior is clearly manifested in Fig. 15 in wide spectral range. This manner of $n$ is very consistent with the reported results of $\mathrm{Ni}$ and $\mathrm{Cr}$ doped $\mathrm{SnO}_{2}$ synthesized by spray pyrolysis deposition technique [42,64], respectively. In Fig. 15, solid lines of different colors represent the fitted lines of the experimentally extracted refractive index dispersion of $\mathrm{Cu}$ doped $\mathrm{ZnO}$. The mathematical formula explaining the fitted line is the two terms Sellmeier dispersion relation, and its form is:

$$
\mathrm{n}(\lambda)=\mathrm{A}+\mathrm{B} / \lambda^{2}
$$

In Eq.9, two constants A and B are employed as fitting parameters. 


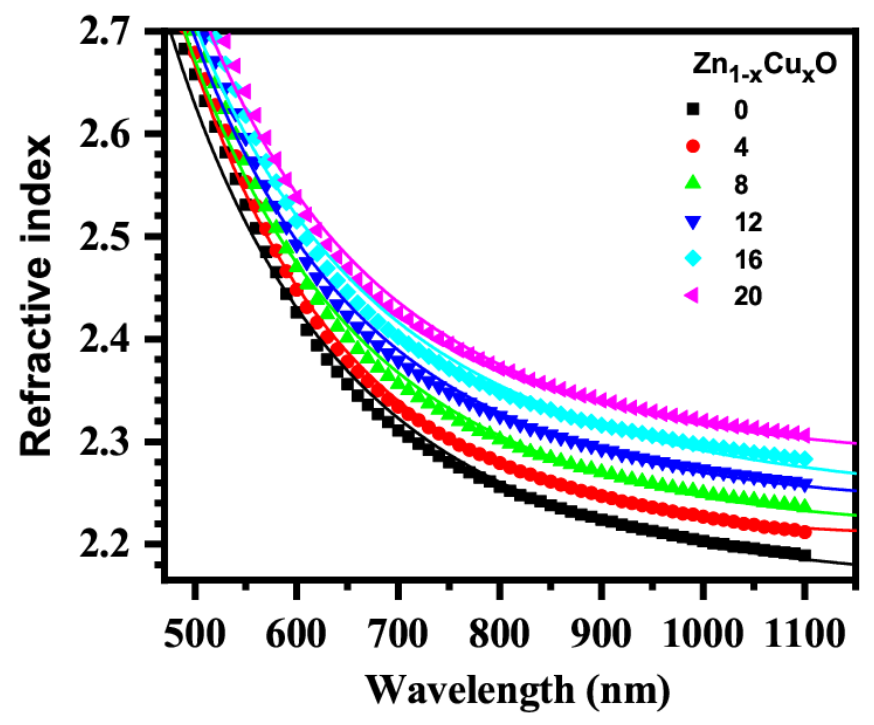

Fig.15. The wavelength dependence of the refractive index of the as-deposited nanostrcutured $\mathrm{Cu}$-doped $\mathrm{ZnO} \mathrm{Cu}$ concentrations 0, 2, 4, 8, 12, 16 and 20 at. \%.

\subsubsection{Optical characteristic of dispersive oscillator parameters}

By applying the Wemple and DiDomencio (WDD) single oscillator model, it is possible to have a deeper understanding of the spectral behavior of the refractive index and the dispersion energy parameter. The mathematical relationship describing the WDD model is $[65,66]$ :

$\mathrm{n}^{2}-1=\frac{\mathrm{E}_{\mathrm{d}} \mathrm{E}_{\mathrm{o}}}{\mathrm{E}_{\mathrm{o}}^{2}-\mathrm{E}^{2}}$

In relation 10 , the factors $\mathrm{n}, \mathrm{E}_{\mathrm{d}}, \mathrm{E}_{\mathrm{o}}$ and $\mathrm{E}=h v$ are index of refraction, dispersion energy, average oscillator energy and energy of the incident photon, respectively. These factors are related directly to the internal structure of the studied film, among them, $E_{d}$ which is related to electronic oscillator strength and $\mathrm{E}_{\mathrm{o}}$ is related to oscillator energy, and consequently to the average energy band gap of the investigated film. By analyzing the energy dependence of the factors $\left(n^{2}-1\right)^{-1}$ verses $\left(E^{2}\right)$ for nanocrystalline $\mathrm{Zn}_{1-\mathrm{x}} \mathrm{Cu}_{\mathrm{x}} \mathrm{O}(0.0 \leq \mathrm{x} \leq 0.2)$ film below the edge of the band gap using WDD model. Rewriting Eq.10, the normal dispersion of the nanocrystalline $\mathrm{Zn}_{1-\mathrm{x}} \mathrm{Cu}_{\mathrm{x}} \mathrm{O}(0.0 \leq \mathrm{x} \leq 0.20)$ film will have the form: 


$$
\left(n^{2}-1\right)^{-1}=\left(\frac{E_{o}}{E_{d}}\right)-\left(\frac{1}{E_{o} E_{d}}\right) E^{2}
$$

Using straight line fitting technique to Eq.11, the calculated values of $E_{o}$ and $E_{d}$ factors are estimated from the graphical representation of $\left(\mathrm{n}^{2}-1\right)^{-1}$ and $(h v)^{2}$ given in Fig. 16. Table 1 lists the WDD oscillator factors calculated for nanocrystalline $\mathrm{Zn}_{1-\mathrm{x}} \mathrm{Cu}_{\mathrm{x}} \mathrm{O}(0.0 \leq \mathrm{x} \leq 0.20)$.

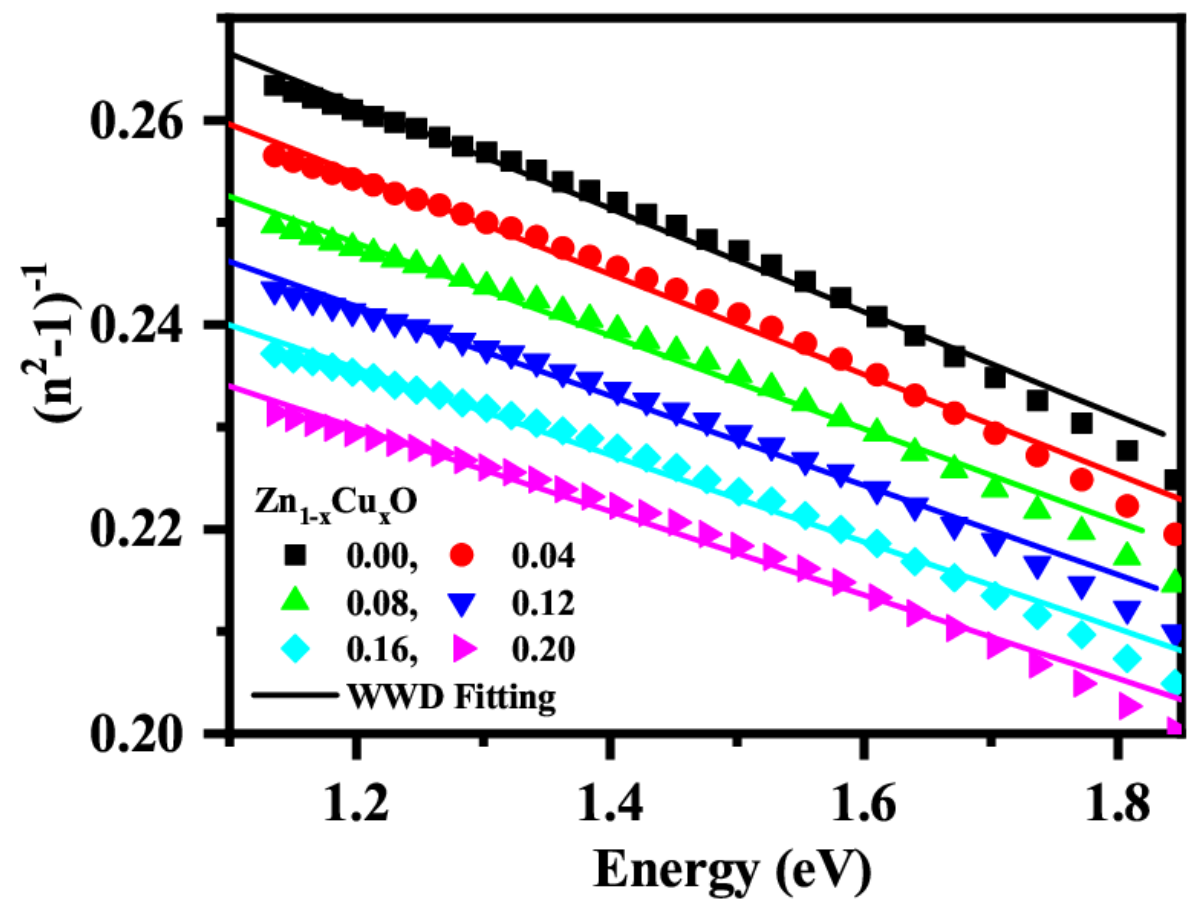

Fig.16. graphical representation of the refractive index factor $\left(n^{2}-1\right)^{-1}$ against incident photon energy $(\mathrm{h} v)^{2}$ for the undoped and $\mathrm{Cu}$ doped $\mathrm{ZnO}$ nanocrystalline thin films.

Obviously, the value of $\mathrm{E}_{\mathrm{o}}$ of the nanocrystalline $\mathrm{Zn}_{1-\mathrm{x}} \mathrm{Cu}_{\mathrm{x}} \mathrm{O}(0.0 \leq \mathrm{x} \leq 0.20)$ film decreases as the percentage of $\mathrm{Cu}$ increases, which is expected because it is related directly to the average band gap of the studied film through an empirical relation of the form $E_{o}=(2 \pm 0.02) E_{g}^{o p t(W D D)}$ [53]. Obviously, WDD approximate optical band gap $E_{g}^{o p t(W D D)}$ is consistent with the values determined from Tauc's graph [67]. Besides, the physical interpretation of WDD formula reveals a strong relationship between $E_{d}$ and the chemical structural changes of the deposited nanocrystalline $\mathrm{Zn}_{1-\mathrm{x}} \mathrm{Cu}_{\mathrm{x}} \mathrm{O}(0.0 \leq \mathrm{x} \leq 0.20)$ film (such as 
lattice structure, chemical bonds, etc.) [Error! Bookmark not defined.]. Therefore, as the $\mathrm{Cu}$ content increases, the increase in $\mathrm{E}_{\mathrm{d}}$ is associated to the increase in the observed lattice parameters, see Fig. 3. Additionally, Table 1 not only contains WDD oscillator parameters $\mathrm{E}_{\mathrm{o}}, \mathrm{E}_{\mathrm{d}}$ but also the corresponding static refractive index $n_{0}=\left(1+E_{d} / E_{o}\right)^{0.5}(\mathrm{n}$ when $\mathrm{E} \rightarrow 0)$ and static dielectric constant $\varepsilon_{o}=n_{o}^{2}$ for nanocrystalline $\mathrm{Zn}_{1-\mathrm{x}} \mathrm{Cu}_{\mathrm{x}} \mathrm{O}(0.0 \leq \mathrm{x} \leq 0.2)$ thin film. Finally, the optical spectra moment parameters for nanocrystalline undoped $\mathrm{ZnO}$ and $\mathrm{Cu}$ doped $\mathrm{ZnO}\left(\mathrm{Zn}_{1-\mathrm{x}} \mathrm{Cu}_{\mathrm{x}} \mathrm{O}(0.0 \leq \mathrm{x} \leq 0.2)\right) M_{-1}$ and $M_{-3}$ are calculated from the single oscillator parameters of WDD $E_{o}$ and $E_{d}$ using the following relations and listed in Table 1 [68]:

$$
\mathrm{M}_{-1}=\frac{\mathrm{E}_{\mathrm{d}}}{\mathrm{E}_{\mathrm{o}}} \quad \mathrm{M}_{-3}=\frac{\mathrm{M}_{-1}}{\mathrm{E}_{\mathrm{o}}^{2}}
$$

Apparently, as $\mathrm{Cu}$ concentration increases, the $M_{-1}$ and $M_{-3}$ decrease. Consequently, the tunability of the optical energy band gap and dispersive oscillator parameters of $\mathrm{Cu}$ doped in the $\mathrm{ZnO}$ semiconductor matrix reveals the opportunity of using nanostructured $\mathrm{Cu}$ doped $\mathrm{ZnO}$ films in the optoelectronic device applications.

Table 1 For undoped $\mathrm{ZnO}$ and $\mathrm{Cu}$-doped $\mathrm{Zn}_{1-\mathrm{x}} \mathrm{Cu}_{\mathrm{x}} \mathrm{O}$ nanocrystalline films, the values of the optical band gap and single oscillator parameters are tabulated.

\begin{tabular}{|c|c|c|c|c|c|c|c|c|}
\hline $\begin{array}{c}\boldsymbol{C u} \\
\boldsymbol{a t} . \boldsymbol{\%}\end{array}$ & $\begin{array}{c}E_{g}^{\text {opt }} \\
(\mathbf{e V})\end{array}$ & $\begin{array}{c}E_{g}^{\text {opt (WDD })} \\
(\boldsymbol{e V})\end{array}$ & $\begin{array}{c}\boldsymbol{E}_{\boldsymbol{d}} \\
(\mathbf{e V})\end{array}$ & $\begin{array}{c}\boldsymbol{E}_{\boldsymbol{o}} \\
(\mathbf{e V})\end{array}$ & $\boldsymbol{n}_{\boldsymbol{o}}$ & $\boldsymbol{\varepsilon}_{\boldsymbol{o}}$ & $\boldsymbol{M}_{-\boldsymbol{1}}$ & $\begin{array}{c}\boldsymbol{M}_{\mathbf{- 3}} \\
(\mathbf{e V})^{-2}\end{array}$ \\
\hline 0 & 3.286 & 3.262 & 7.800 & 6.524 & 2.031 & 4.125 & 0.322 & 0.051 \\
4 & 3.211 & 3.201 & 8.070 & 6.201 & 2.056 & 4.227 & 0.316 & 0.049 \\
8 & 3.146 & 3.123 & 8.530 & 6.246 & 2.082 & 4.335 & 0.303 & 0.046 \\
12 & 3.046 & 3.011 & 8.700 & 6.022 & 2.109 & 4.448 & 0.302 & 0.044 \\
16 & 2.970 & 2.956 & 9.110 & 5.912 & 2.138 & 4.571 & 0.286 & 0.042 \\
20 & 2.934 & 2.913 & 9.350 & 5.826 & 2.169 & 4.705 & 0.278 & 0.041 \\
\hline
\end{tabular}




\section{Conclusions}

Nanocrystalline $\mathrm{Cu}$-doped $\mathrm{ZnO}$ thin films with various $\mathrm{Cu}$ concentrations were prepared using e-beam deposition technique. The physical properties of the nanocrystalline $\mathrm{Cu}$-doped $\mathrm{ZnO}$ films were studied by using different characterization methods such as $\mathrm{XRD}$, EDXS, AFM and SE. The XRD spectrum of $\mathrm{Zn}_{1-\mathrm{x}} \mathrm{Cu}_{\mathrm{x}} \mathrm{O}(0.0 \leq \mathrm{x} \leq 0.1)$ nanocrystalline film shows the formation of a hexagonal wurtzite type structure without any additional phases. The morphology analysis shows that the grain size and the surface roughness decrease with increasing of the $\mathrm{Cu}$ doping level which is confirmed from XRD and SE investigations, respectively. It was found that the direct energy gap of the $\mathrm{Zn}_{1-\mathrm{x}} \mathrm{Cu}_{\mathrm{x}} \mathrm{O}(0.0 \leq \mathrm{x} \leq 0.2)$ nanocrystalline film decreases with the increase of $\mathrm{Cu}$ content. The direct optical energy band gap reduction of the studied film is ascribed to the sp-d exchange interaction. The refractive index dispersion shows that as the $\mathrm{Cu}$ doping level raises, the refractive index enhances. The variation of the optical energy band gap and the evaluated dispersive oscillator parameters values $E_{o}, E_{d}, n_{0}, \varepsilon_{0}, M_{-1}$ and $M_{-3}$ with the increase of the $\mathrm{Cu}$ doping level confirm that $\mathrm{Cu}$ doped $\mathrm{ZnO}$ films are good candidate for optoelectronic device applications.

\section{Acknowledgment}

The authors extend their appreciation to the Deanship of Scientific Research at King Khalid University for funding this work through General Research Project under grant number $1 / 224 / 41$

\section{6- References}

[1] A. Moulahi and F. Sediri, Pencil-like zinc oxide micro/nano-scale structures: Hydrothermal synthesis, optical and photocatalytic properties, Mater. Res. Bull. 48 (2013), 3723-3728.

[2] C. F. Klingshirn, A. Waag, A. Hoffmann, J. Geurts, Zinc oxide: from fundamental properties towards novel applications. Heidelberg: Springer; 2010. 
[3] Xu Fen, Zhang Peng, Navrotsky Alexandra, Yuan Zhong-Yong, Ren Tie-Zhen, Halasa Matej, Su Bao-Lian, Hierarchically assembled porous ZnO nanoparticles: synthesis, surface energy, and photocatalytic activity. Chem. Mater. 23 (2007), 5680-5686.

[4] A. B. Martinson, J. W. Elam, J. T. Hupp, M. J. Pellin, ZnO nanotube based dyesensitized solar cells. Nano. Lett. 7 (2007), 2183-2187.

[5] R. Wang, J. Xin, X. Tao, UV-blocking property of dumbbell-shaped ZnO crystallites on cotton fabrics. Inorg. Chem. 44 (2005), 3926-3930.

[6] R. K. Shukla, Anchal Srivastava, Nishant Kumar, Akhilesh Pandey, and Mamta Pandey, Journal of Nanotechnology, 2015, (2015),172864-172874.

[7] Y. Caglar, S. Aksoy, S. Ilican, M. Caglar, Crystalline structure and morphological properties of undoped and $\mathrm{Sn}$ doped $\mathrm{ZnO}$ thin flms. Superlattices and Microstructure. 46 (2009) 469-475.

[8] L. P. Peng, L. Fang, X.F. Yang, Y.J. Li, Q.L. Huang, F. Wu, C.Y. Kong, Efect of annealing temperature on the structure and optical properties of In-doped $\mathrm{ZnO}$ thin flms. J. Alloys. Comp. 484 (2009) 575-579.

[9] X. C. Wang, X.M. Chen, B.H. Yang, Microstructure and optical properties of polycrystalline $\mathrm{ZnO}$ flms sputtered under diferent oxygen fow rates. J. Alloys. Comp. 488 (2009) 232-237.

[10] G. Zhu, G. Shulin, S. Zhu, S. Huang, G. Ran, J. Ye, Y. Zheng, Optimization study of metal-organic chemical vapor deposition of $\mathrm{ZnO}$ on sapphire substrate. J. Cryst. Growth. 349 (2012) 6-11.

[11] S. Aksay, Y. Caglar, S. Ilican, M. Caglar, Sol-gel derived zinc oxide flms: effect of deposition parameters on structure, microstructure and photoluminescence properties. Superlattices and Microstruct. 50 (2011) 470-479.

[12] S.J. Jiao, Y.M. Lu, D.Z. Shen, Z.Z. Zhang, B.H. Li, ZhH Zheng, B. Yao, J.Y. Zhang, D. Zhao, X.W. Fan, Donor-acceptor pair luminescence of nitrogen doping p-type ZnO by plasma- assisted molecular beam epitaxy, J. Lumines. 122 (2007) 368-370.

[13] A.I. Savchuk, V.I. Fediv, S.A. Savchuk, A. Perrone, Growth and characterization of ZnMnO thin flms. Superlattices Microstruct. 38 (2005), 421-427.

[14] ChY Tsay, KSh Fan, ChM Lei, Synthesis and characterization of sol-gel derived gallium-doped zinc oxide thin flms. J. Alloys. Comput. 512 (2012) 216-222. 
[15] B. Dominic, M. Franziska, F. Martin, K. Steffen, K.h Richard, B. Dietmar, W. Martin, P. Elie, P. Stefano, Transition-metal-doped zinc oxide nanoparticles as a new lithium-ion anode material. Chem. Mater. 25 (2013) 4977-4985.

[16] B. Allabergenov, S. H. Chung, S. M. Jeong, S. Kim, B. Choi, Enhanced blue photoluminescence realized by copper diffusion doping of $\mathrm{ZnO}$ thin films. Opt. Mater. Exp. 3 (2013) 1733-1741.

[17] A. M. Ganose and D. O. Scanlon, J. Mater. Chem. 4 (2016) 1467-1475.

[18] X.-Y. Feng, Z. Wang, C.-W. Zhang, and P.-J. Wang, J. Nanomater. 2013, (2013).181979-181986.

[19] Q. Wen-Jing, S. Jing, Y. Jing, D. Xi-Wen, Control of Cu-doping and optical properties of $\mathrm{ZnO}$ quantum dots by laser ablation of composite targets, Materials Chemistry and Physics 130 (2011) 425-430.

[20] M. Chakraborty, A. Ghosh, R. Thangavel, Experimental and Theoretical Investigations of Structural and Optical Properties of Copper Doped ZnO Nanorods, Journal of Sol-Gel Science and Technology, 74 (2015)756-764.

[21] B. K. Das, T. Das, K. Parashar, A. Thirumurugan, S. K. S. Parashar, Structural, band gap tuning and electrical properties of $\mathrm{Cu}$ doped $\mathrm{ZnO}$ nanoparticles synthesized by mechanical alloying, Journal of Materials Science: Materials in Electronics, 28 (2017) $15127-15134$.

[22] Z. N. Kayani, S. Iram, R. Rafi, Effect of Cu Doping on The Structural, Magnetic and Optical Properties of ZnO Thin Films. Appl. Phys A. Mater. Sci. Process. 124 (2018) 468-470.

[23] S. Ouidette, D Djamel, H. Laid, Structural and Optical Properties of Cu Doped ZnO Aerogels Synthesized in Supercritical Ethanol, J. Porous Mater. 25 (2018) 595-601.

[24]M. Fang, C. M. Tang, Z. W. Liu, Microwave-Assisted Hydrothermal Synthesis of Cu Doped $\mathrm{ZnO}$ Single Crystal Nanoparticles with Modified Photoluminescence and Confirmed Ferromagnetism. J. Electron. Mater. 47 (2018) 1390-1396.

[25] M. Zhanhong, R. Fengzhang, M. Xiaoli , L. Yongqiang and A. A. Volinsky, Cu-Doped $\mathrm{ZnO}$ Electronic Structure and Optical Properties Studied by First-Principles Calculations and Experiments, Materials 12 (2019) 196-208.

[26] M. El-Hagary, M. Emam-Ismail, E. R. Shaaban, A. El-Taher, Effect of $\gamma$ - irradiation exposure on optical properties of chalcogenide glasses $\mathrm{Se}_{70} \mathrm{~S}_{30-\mathrm{x}} \mathrm{Sb}_{\mathrm{x}}$ thin films, Radiat. Phys. Chem. 81 (2012) 1572-1577. 
[27] M. Emam-Ismail, E. R. Shaaban, M. El-Hagary, I. Shaltout, Optical investigation of electron-beam deposited tungsten-tellurite $\left(\mathrm{TeO}_{2}\right)_{100-\mathrm{x}}\left(\mathrm{WO}_{3}\right)_{\mathrm{x}}$ amorphous films, Philos. Mag. 90 (2010) 3499-3509.

[28] M. El-Hagary, M. Emam-Ismail, S. H. Mohamed, A. S. Hamid, S. Althoyaib, Structural and optical analysis of nanocrystalline thin films of mixed rare earth oxides $\left(\mathrm{Y}_{1-\mathrm{x}} \mathrm{Er}_{\mathrm{x}}\right)_{2} \mathrm{O}_{3}$, Thin Solid Films 518 (2010) 4058-4065.

[29] M. Emam-Ismail, M. El-Hagary, E. R. Shaaban, A. M. Al-Hedeib, Microstructure and optical studies of electron beam evaporated $\mathrm{ZnSe}_{1-\mathrm{x}} \mathrm{Te}_{\mathrm{x}}$ nanocrystalline thin films, J. Alloy. Comp. 532 (2012) 16-24.

[30] E. R. Shaaban, M. El-Hagary, M. Emam-Ismail, M. B. El-Den, Optical band gap refractive index dispersion and single oscillator parameters of amorphous $\mathrm{Se}_{70} \mathrm{~S}_{30-\mathrm{x}} \mathrm{Sb}_{\mathrm{x}}$ semiconductor thin films, Phil. Mag. 91 (2011) 1679-1692.

[31] M. El-Hagary, M.Emam-Ismail, E . R. Shaaban, I. Shaltout, Optical properties of glasses $\left(\mathrm{TeO}_{2}-\mathrm{GeO}_{2}-\mathrm{K}_{2} \mathrm{O}\right)$ thin films co-doped with rare earth oxides $\mathrm{Sm}_{2} \mathrm{O}_{3} / \mathrm{Yb}_{2} \mathrm{O}_{3}$, J. Alloy. Comp., 485 (2009), 519-523.

[32] M. El-Hagary, S.H. Moustafa, H. Hashem, E.R. Shaaban, M. Emam-Ismail, Influences of Mn doping on the microstructural, semiconducting, and optoelectronic properties of $\mathrm{HgO}$ nanostructure films, Journal of the American Ceramic Society 102 (2019) 47374747.

[33] E. R. Shaaban, M. Emam-Ismail, Gh. Abbady, Deo. Prakash, M. El-Hagary, N. Afify, K. D. Verma, Investigation of optical properties of amorphous $\mathrm{Ge}_{15} \mathrm{Se}_{85-\mathrm{x}} \mathrm{Cu}_{\mathrm{x}}$ thin films using spectroscopic ellipsometry, Solid State Sci. 52 (2016) 65-71.

[34] E. R. Shaaban, M. El-Hagary, M. Emam-Ismail, A. M. AbdElnaiem, S. H. Moustafa, A. Adel, Optical characterization of polycrystalline $\mathrm{ZnSe}_{1-\mathrm{x}} \mathrm{Te}_{\mathrm{x}}$ thin films using variable angle spectroscopic ellipsometry and spectrophotometry techniques, Mater. Sci. Semicond. Process. 39 (2015) 735-741.

[35] E. R. Shaaban, M. El-Hagary, M. Emam-Ismail, A. Matar, I. S. Yahia, Spectroscopic ellipsometry and magneto-transport investigations of Mn-doped ZnOnanocrystalline films deposited by a non-vacuum sol-gel spin-coating method, Mater. Sci. Eng., B178 (2013) 183-189.

[36] M.-H. Cho, D.-H. Ko, K. Jeong, S. W. Whangbo, and C. N. Whang, Growth stage of crystalline $\mathrm{Y}_{2} \mathrm{O}_{3}$ film on $\mathrm{Si}(100)$ grown by an ionized cluster beam deposition, Journal of Applied Physics 85 (1999) 2909-2914. 
[37] E. R. Shaaban, M. El-Hagarya, M. Emam-Ismail, A. Matarc, I. S. Yahia, Spectroscopic ellipsometry and magneto-transport investigations of $\mathrm{Mn}$-doped $\mathrm{ZnO}$ nanocrystalline films deposited by a non-vacuum sol-gel spin-coating method, Materials Science and Engineering B 178 (2013) 183- 189.

[38] T. Saidani, M. Zaabat, M.S. Aida, B. Boudine, Effect of Copper Doping on the Photocatalytic Activity of ZnO Thin Films Prepared by Sol-gel Method, Superlattices Microstruct., 88 (2015) 315-322.

[39] J. Hays, A. Punnoose, R. Baldner, M. H. Engelhard, J. Peloquin, and K. M. Reddy, Relationship Between the Structural and Magnetic Properties of Co-Doped SnO2 Nanoparticles, Phys. Rev. B 72 (2005) 075203.

[40] N. H. Hong, J. Sakai, W. Prellier, A. Hassini, Transparent Cr doped $\mathrm{SnO}_{2}$ thin films ferromagnetism beyond room temperature with a giant magnetic moment. J. Phys. C. Condens. Matter. 17, (2005), 1697-1702.

[41] A. Azam, A.S. Ahmed, S.S. Habib, A.H. Naqvi, Effect of Mn doping on the structural and optical properties of $\mathrm{SnO}_{2}$ nanoparticles, J. Alloys Compd. 523 (2012) 83- 87.

[42] M. I. Amer, S. H. Moustafa, M. El-Hagary, Enhanced band structure, optoelectronic and magnetic properties of spray pyrolysis Ni-doped $\mathrm{SnO}_{2}$ nanostructured films, Mater. Chem. Phys., 248 (2020), 122892-122905.

[43] J. J. Attema, G. A. de. Wijs and R. A. de. Groot, Spintronic materials based on maingroup elements, J. Phys.: Condens. Matter 19 (2007) 165203-165214.

[44] M. Emam-Ismail, M. El-Hagary, E. R. Shaaban, S. H. Moustafa, G. M. A. Gad, Spectroscopic ellipsometry and morphological characterizations of nanocrystalline $\mathrm{Hg}_{1}$ ${ }_{x} \mathrm{Mn}_{\mathrm{x}} \mathrm{O}$ oxide diluted magnetic semiconductor thin films, Ceram. Int. 45 (2019) 83808387.

[45] M. Emam-Ismail, M. El-Hagary, H. M. El-Sherif, A. M. El-Naggar, M. M. El-Nahass, Spectroscopic ellipsometry and morphological studies of nanocrystalline $\mathrm{NiO}$ and $\mathrm{NiO} / \mathrm{ITO}$ thin films deposited by e-beams technique, Optical materials 112 (2021), 110763-110777.

[46] M. Thangaraju, A. Jayaram, R. Kandasamy, Structural, morphological, optical and electrical properties of e-beam deposited nanocrystalline $\mathrm{CdTe}: \mathrm{Cu}$ alloy thin films from mechanical alloyed samples, Appl. Surf. Sci. 449 (2018), 2-9.

[47] H. G. Tompkins and J. N. Hilfiker, Spectroscopic ellipsometry Practical Application to Thin Film Characterization, Momentum press LLC, New York, 2016. 
[48] H. Fujiwara, Spectroscopic Ellipsometry Principles and Applications, John Wiley \& Sons Ltd, West Sussex, England, 2007.

[49] E. R. Shaaban, M. El-Hagary, M. Emam-Ismail, A. M. AbdElnaeim, S. H. Moustafa, A. Adel, Optical characterization of polycrystalline $\mathrm{ZnSe}_{1-\mathrm{x}} \mathrm{Te}_{\mathrm{x}}$ thin films using variable angle spectroscopic ellipsometry and spectrophotmetery techniques, Materials Science in Semiconductor Processing, 39, (2015), 735-741.

[50] G. E. Jellison, Spectroscopic ellipsometry data analysis: measured versus calculated quantities, Thin Solid Films. 313-314 (1998) 33-39

[51] M. Emam-Ismail, M. El-Hagary, E. R. Shaaban, S. H. Moustafa, G. M. A. Gad, Spectroscopic ellipsometry and morphological characterizations of nanocrystalline $\mathrm{Hg}_{1-}$ ${ }_{x} \mathrm{Mn}_{\mathrm{x}} \mathrm{O}$ oxide diluted magnetic semiconductor thin films, Ceram. Int. 45 (2019) 83808387.

[52] M. Emam-Ismail, M. El-Hagary, H. M. El-Sherif, A. M. El-Naggar, M. M. El-Nahass, Spectroscopic ellipsometry and morphological studies of nanocrystalline $\mathrm{NiO}$ and $\mathrm{NiO} / \mathrm{ITO}$ thin films deposited by e-beams technique, Optical materials 112 (2021), 110763-110777.

[53] E. R. Shaaban, M. El-Hagary, M. Emam-Ismail, A. Matar, I. S. Yahia, Spectroscopic ellipsometry and magneto-transport investigations of Mn-doped ZnOnanocrystalline films deposited by a non-vacuum sol-gel spin-coating method, Materials Science and Engineering B: 178, (2013), 183-189.

[54] H. R. Philipp, In Handbook of optical constants of solids, edited by E. D. Palik Academic press, New York, 1985.

[55] G. A. Niklasson, C. G. Granqvist and O. Hunderi, Effective medium models for the optical properties of inhomogeneous materials, Appl. Opt.20 (1981)26-30.

[56] J. Shuvendu, R. B. Tokas, N. M. Kamble, S. Thakur and N. K. Sahoo, Optical properties and laser damage threshold of $\mathrm{HfO}_{2}-\mathrm{SiO}_{2}$ mixed composite thin films, Appl. Opt.53 (2014) 850-860.

[57] A. S. Ferlauto, et al., Analytical model for the optical functions of amorphous semiconductors from the near-infrared to ultraviolet: Applications in thin film photovoltaics, J. Appl. Phys. 92 (2002) 2424-2436.

[58] J. Tauc, Amorphous and Liquid Semiconductor, Plenum, New York, (1974).

[59]R. C. Rai, M. Guminiak, S. Wilser, B. Cai, and M. L. Nakarmi, Elevated temperature dependence of energy band gap of $\mathrm{ZnO}$ thin films grown by e-beam deposition, Journal of Applied Physics 111 (2012) 073511-073517. 
[60] M. Zhanhong, R. Fengzhang, M. Xiaoli, L. Yongqiang and A. A. Volinsky, Cu-Doped $\mathrm{ZnO}$ Electronic Structure and Optical Properties Studied by First-Principles Calculations and Experiments, materials, Materials 196 (2019) 1-12.

[61] S. Horzum, E. Torun, T. Serin and F. M. Peeters, Structural, electronic and optical properties of $\mathrm{Cu}$-doped $\mathrm{ZnO}$ : experimental and theoretical investigation, Philosophical magazine 96 (2016) 1743-1756.

[62] A. Sreedhar, J. Hyuk Kwon, Y. Jonghoon, J. Su Kim, J. Seog Gwag, Enhanced photoluminescence properties of $\mathrm{Cu}$-doped $\mathrm{ZnO}$ thin films deposited by simultaneous RF and DC magnetron sputtering, Materials Science in Semiconductor Processing 49 (2016) 8-14.

[63] Elliott. The physics and chemistry of solids.Chichester: Wiley; 2000.

[64] I. M. El Radaf, Talaat A. Hameed, G.M. El komy, T.M. Dahy, Synthesis, structural, linear and nonlinear optical properties of chromium doped $\mathrm{SnO}_{2}$ thin films, Ceramics International 45 (2019) 3072-3080.

[65] S. H. Wemple, M. Jr. DiDomenico, Behavior of the electronic dielectric constant in covalent and ionic materials, Phys. Rev. B 3 (1971) 1338-1351.

[66] S. H. Wemple, Refractive-Index Behavior of Amorphous Semiconductors and Glasses, Phys. Rev. B 7 (1973) 3767-3777.

[67] K. Tanaka, Thin Solid Films 66 (1980) 271-279.

[68] S. H. Wemple, M. DiDomenico, Phys. Rev. Lett. 23 (1969) 115-118 
Figures
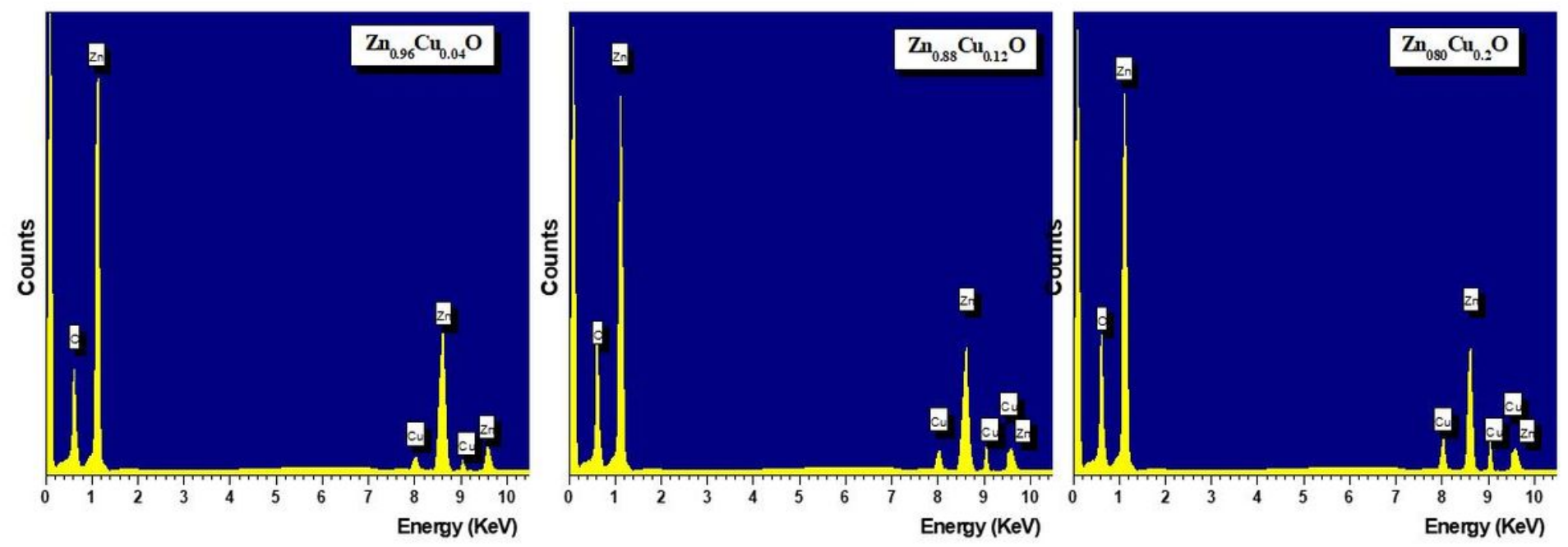

Figure 1

EDXS analysis of the $\mathrm{Cu}(0.04,0.12$, and 0.20$)$ doped $\mathrm{ZnO}$ film.
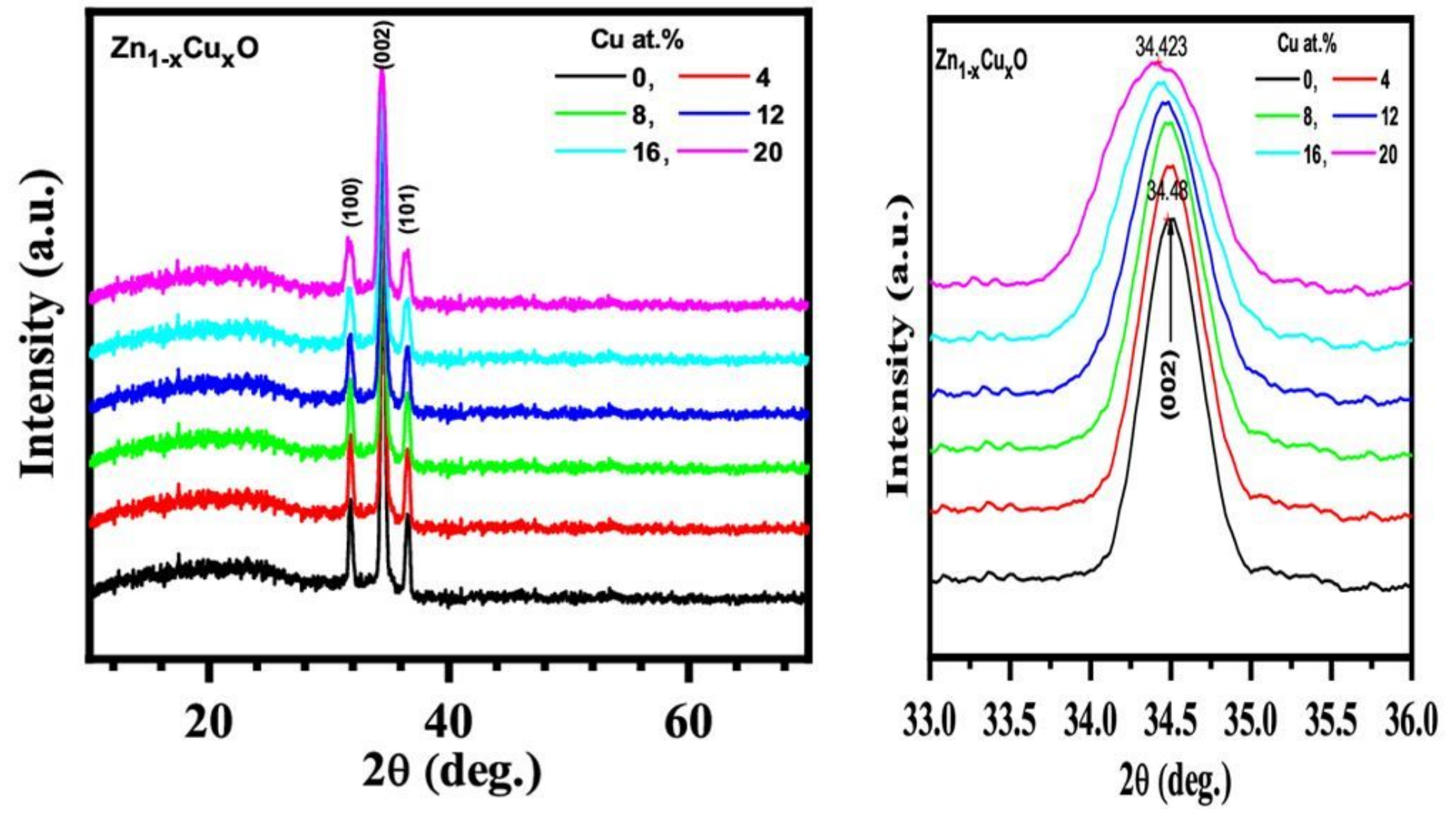

Figure 2

(a) XRD spectra of Cu doped $\mathrm{ZnO}$ thin films with different $\mathrm{Cu} 0,2,4,8,12,16$ and 20 at. \%. , (b) The enlargement of the main diffraction peak (002) of Cu-doped ZnO film. 


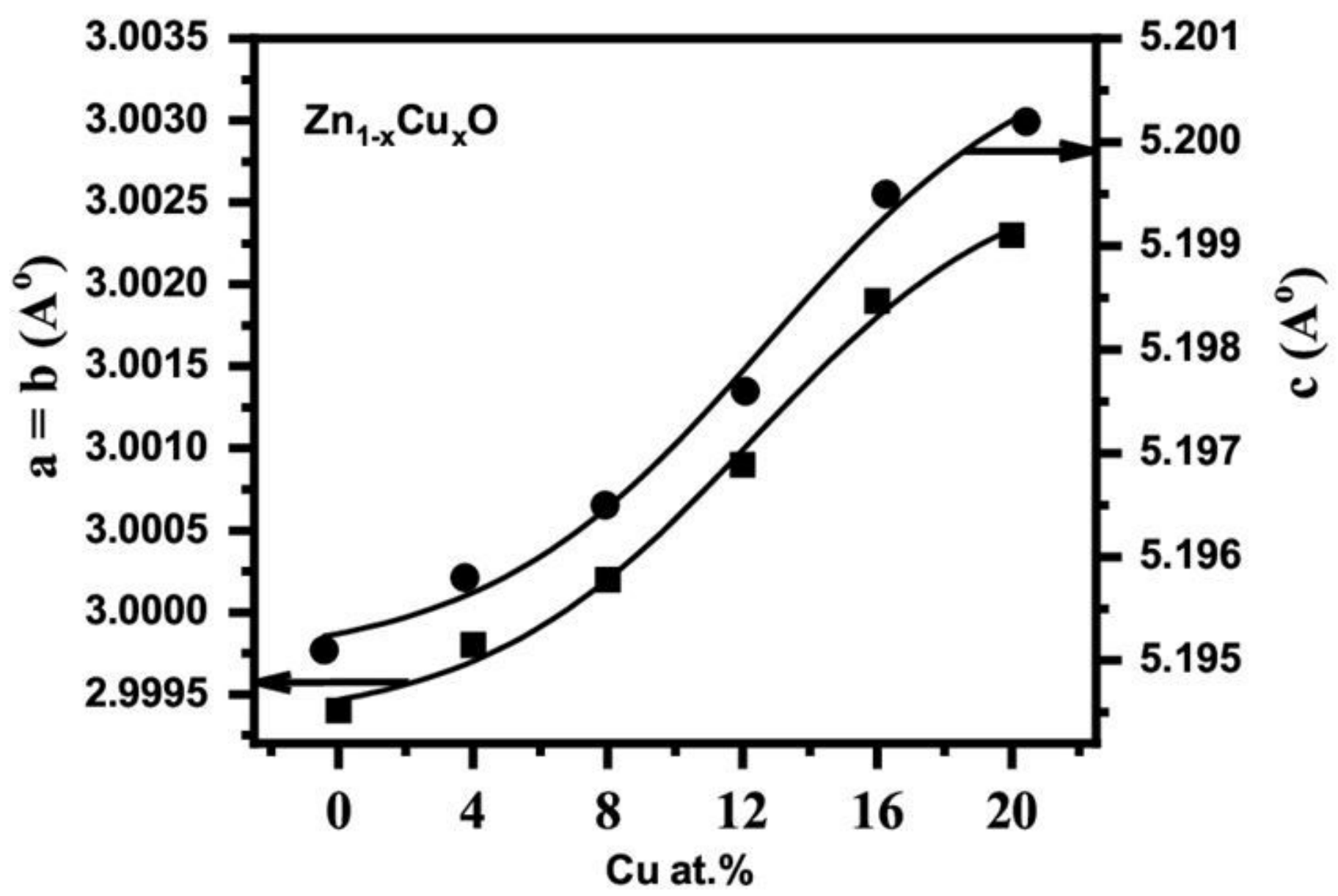

Figure 3

The change of the lattice constant $\mathrm{a}(\AA \AA \AA)$ and $c(\AA)$ in $\mathrm{ZnO}$ matrix with Cu content $(0.0,0.04,0.08,0.12,0.16$, $0.2)$ 


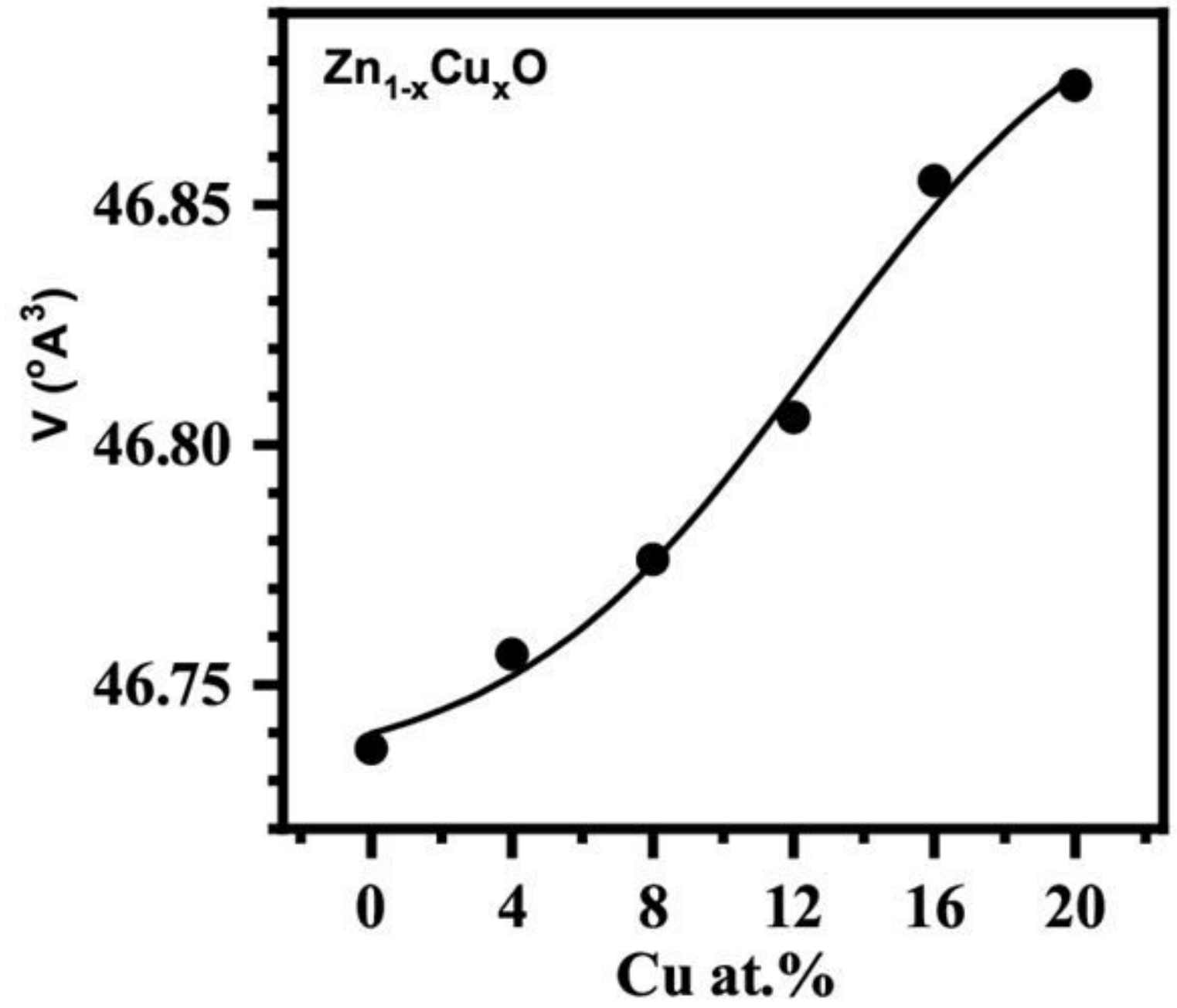

Figure 4

The change of unit cell volume in $\mathrm{ZnO}$ matrix with Cu content $(0.0,0.04,0.08,0.12,0.16$, and 0.20$)$. 


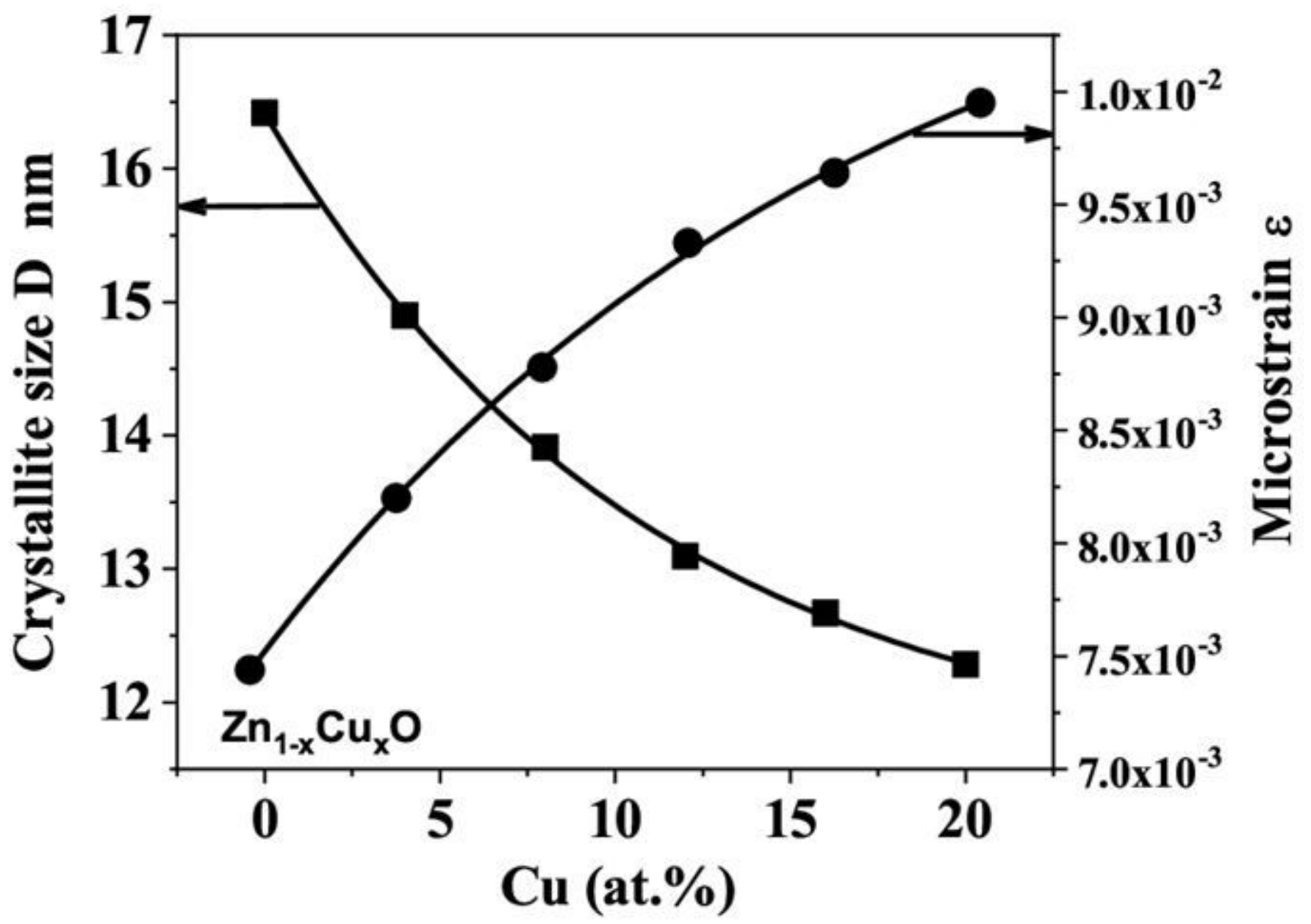

Figure 5

The change of the crystallite size $D$ lattice strain $\varepsilon$ in $\mathrm{ZnO}$ matrix with various $\mathrm{Cu}$ contents $(0,4,8,12,16$, 20 at. \%).

(a)

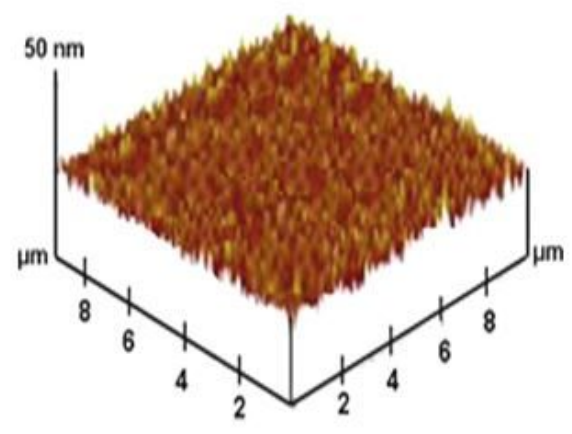

(b)

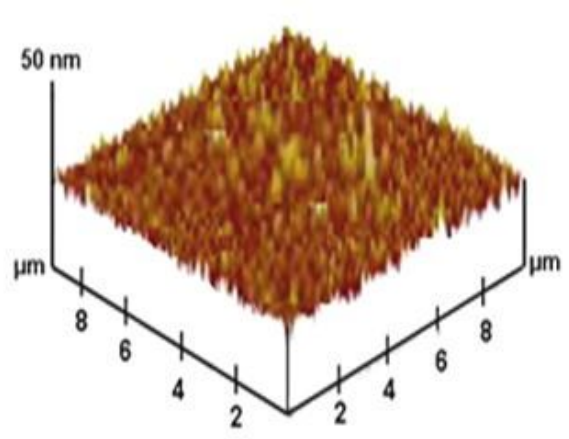

(c)

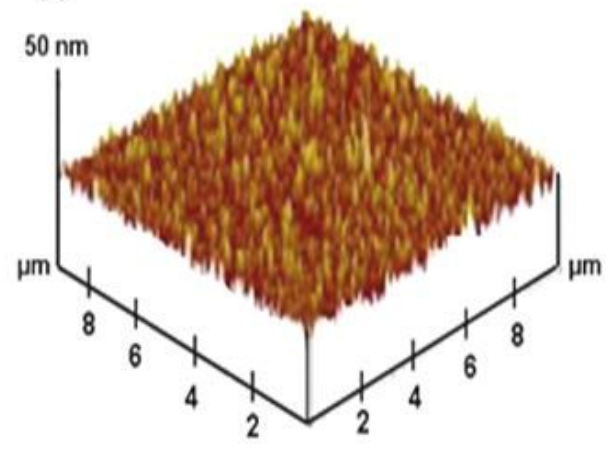

Figure 6

3D-AFM images of (a) ZnO (x=0) film (b) Zn0.92Cu0.080 and Zn0.84Cu0.160 film. 


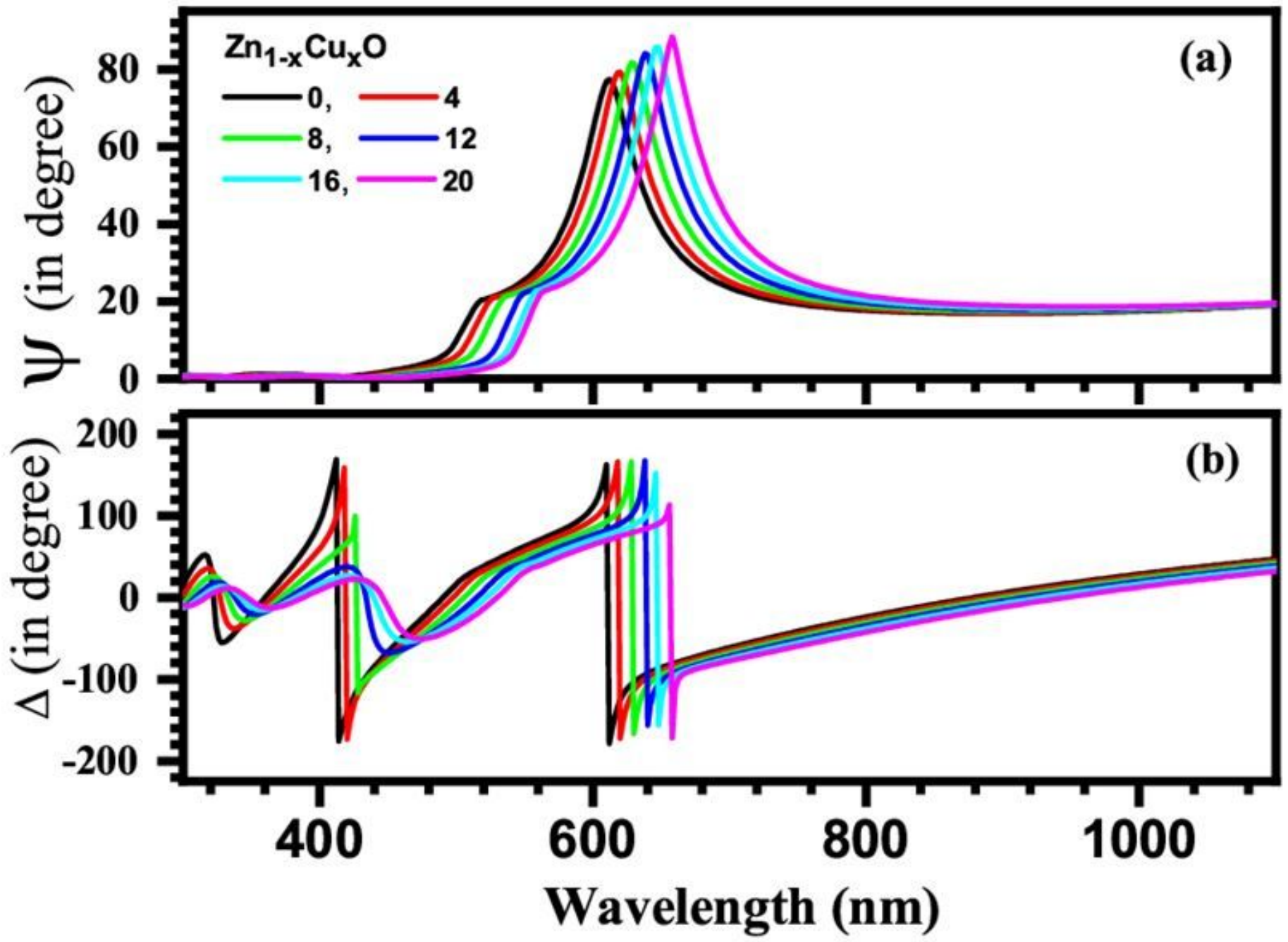

Figure 7

$(a, b)$. For different Cu concentration $(x=0.0,0.04,0.08,0.12,0.16,0.2) \mathrm{ZnO}$ film, the spectral characteristics of the SE parameters $\psi$ and $\Delta$ with wavelength is measured at the incident angle $\theta=70 \mathrm{o}$ 


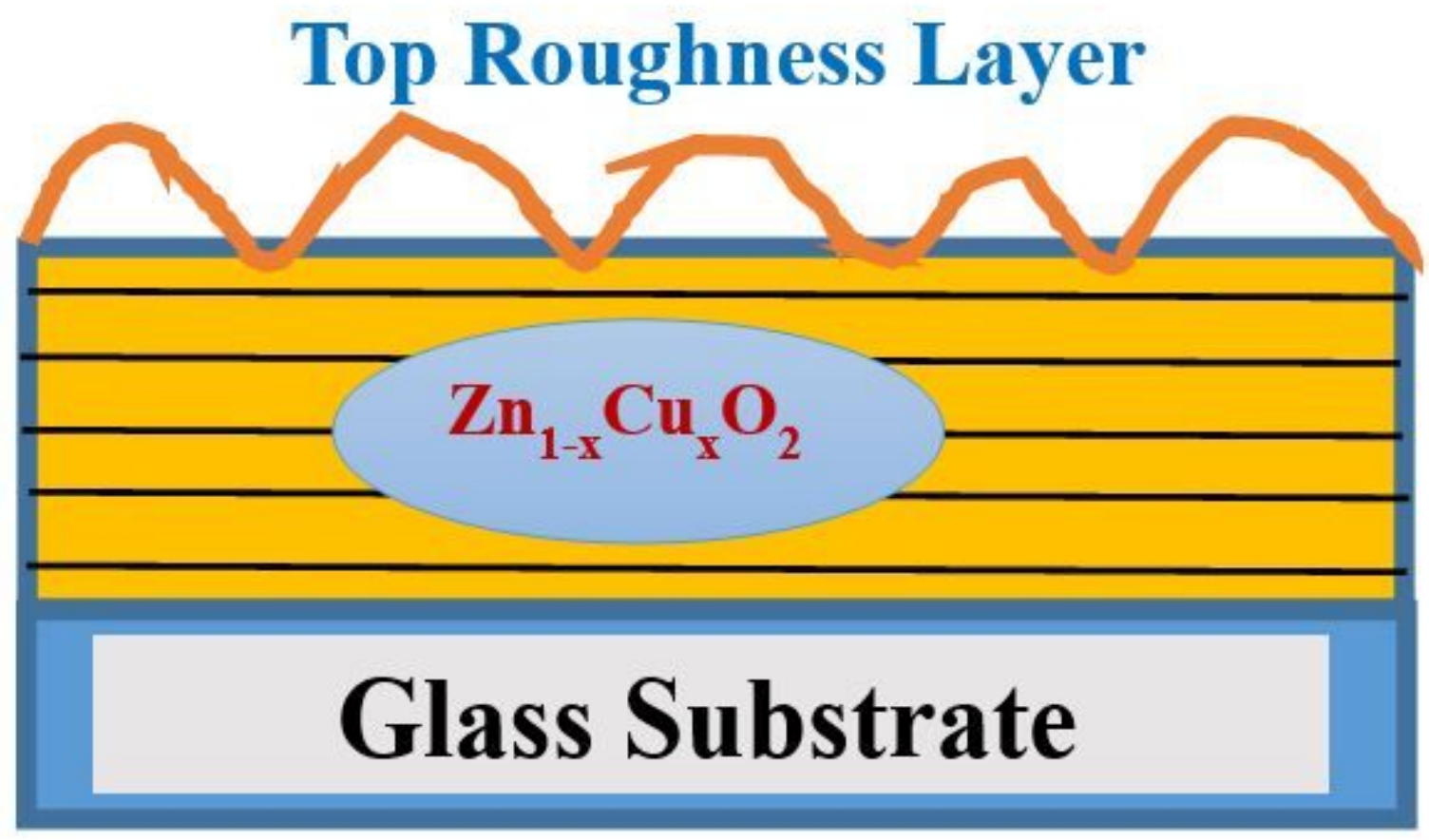

Figure 8

An optical model constructed for describing measured SE spectrum of Zn1-xCuxO thin film settle on silica substrate. 


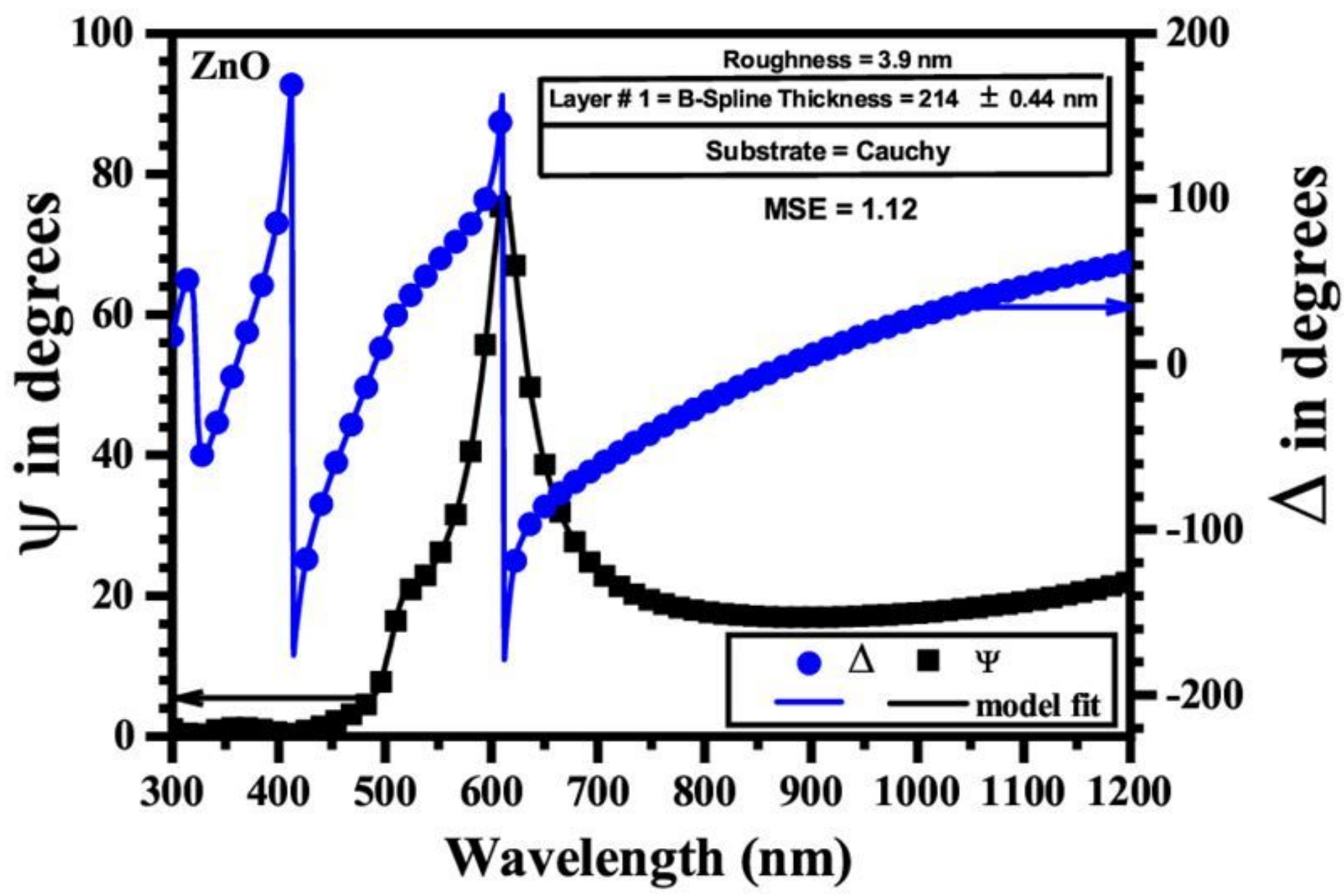

Figure 9

the $\psi$ and $\Delta$ spectra obtained by the SE measurements (black square and blue dots) of the ZnO sample at an incident angle of $70^{\circ}$. The solid line of different colors represents the calculated data (fitted) produced by the three-layer model. 


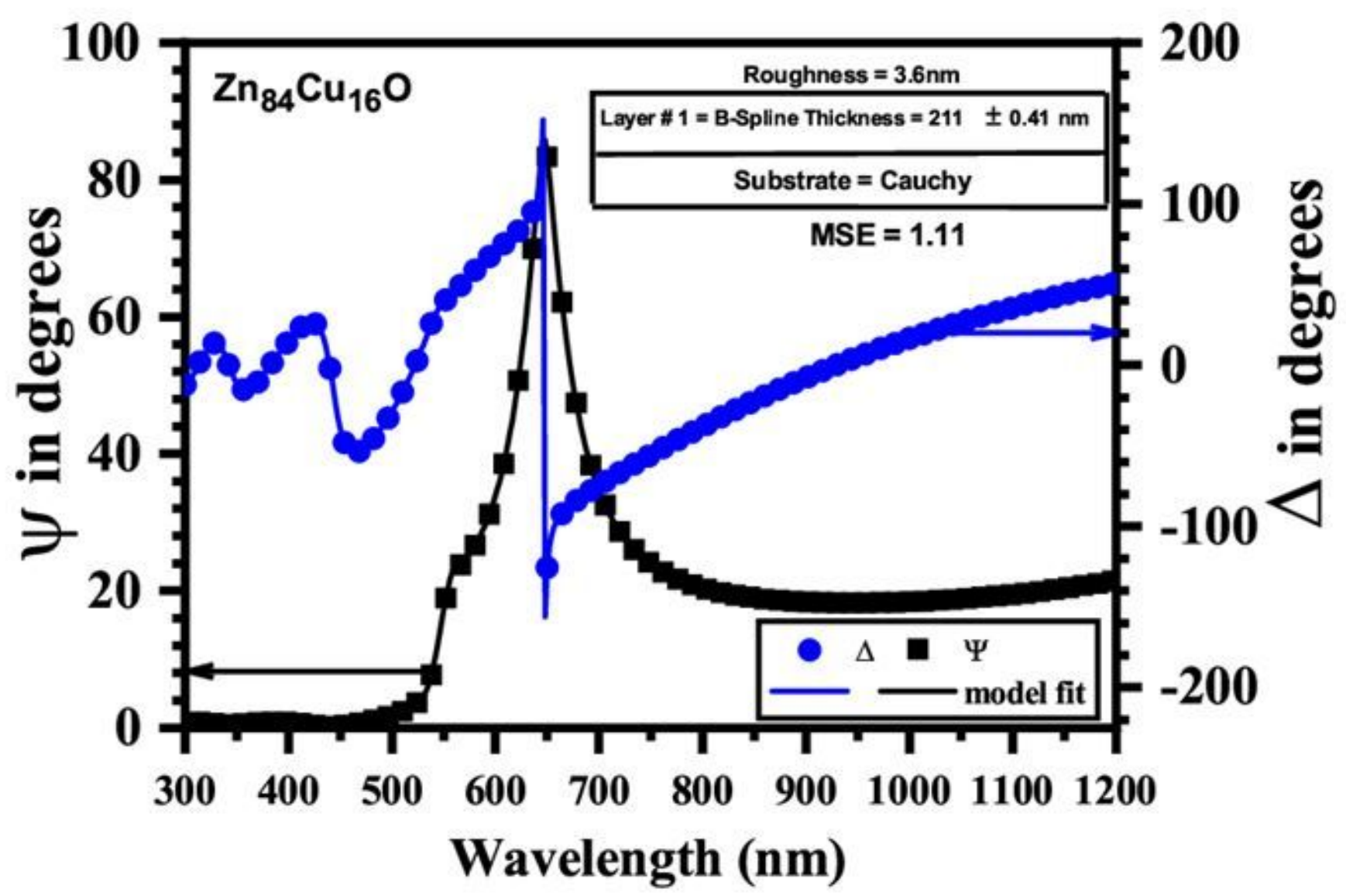

Figure 10

The $\psi$ and $\Delta$ spectra obtained by the SE measurements (black square and blue dots) of the

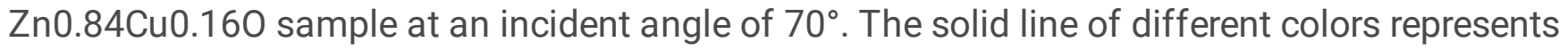
calculated data (fitted) produced by the three-layer model. 


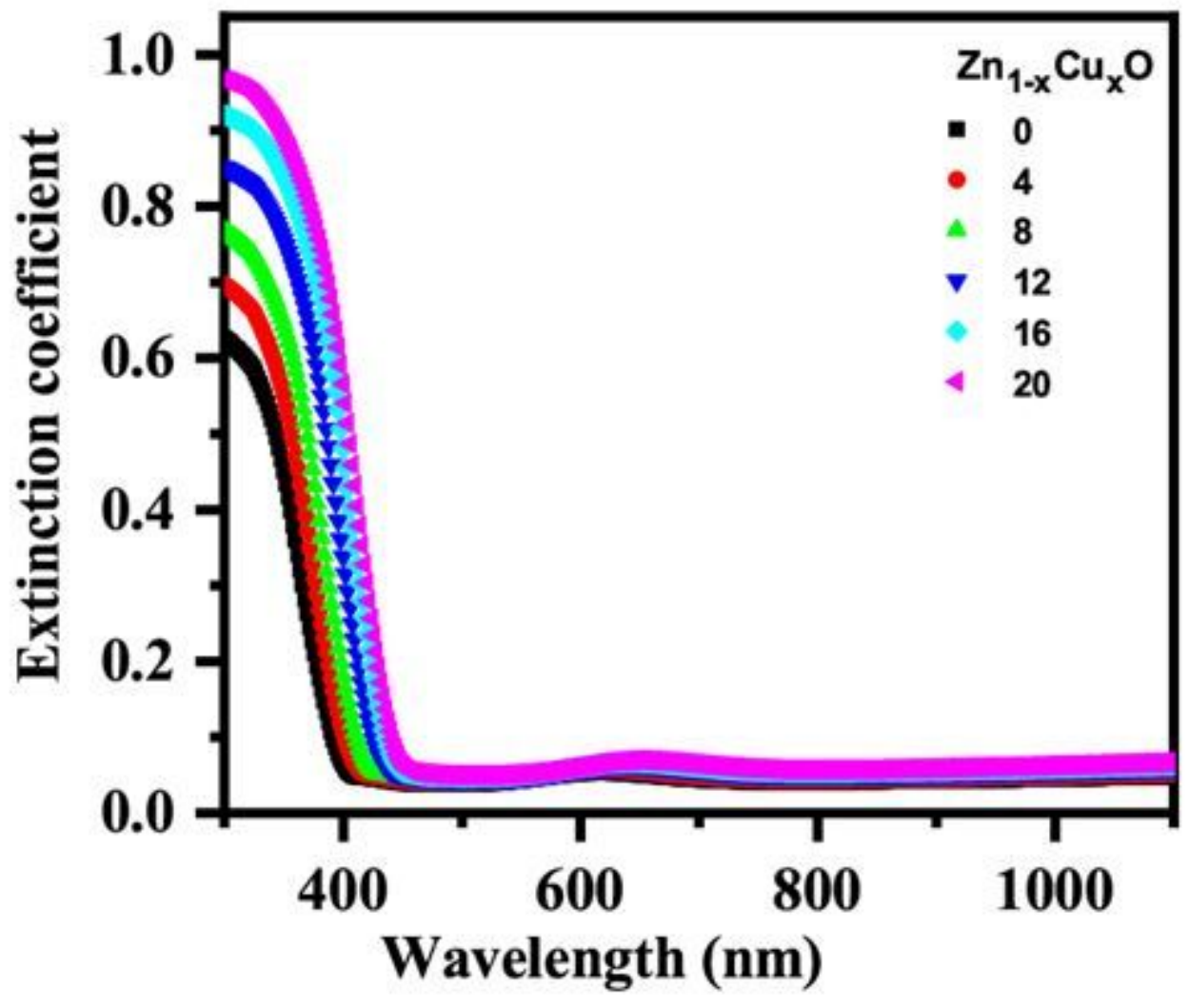

Figure 11

The extinction coefficient of $\mathrm{Cu}$ doped $\mathrm{ZnO}$ thin film versus wavelength with different $\mathrm{Cu}$ concentrations $0,2,4,8,12,16$ and 20 at. \%. 


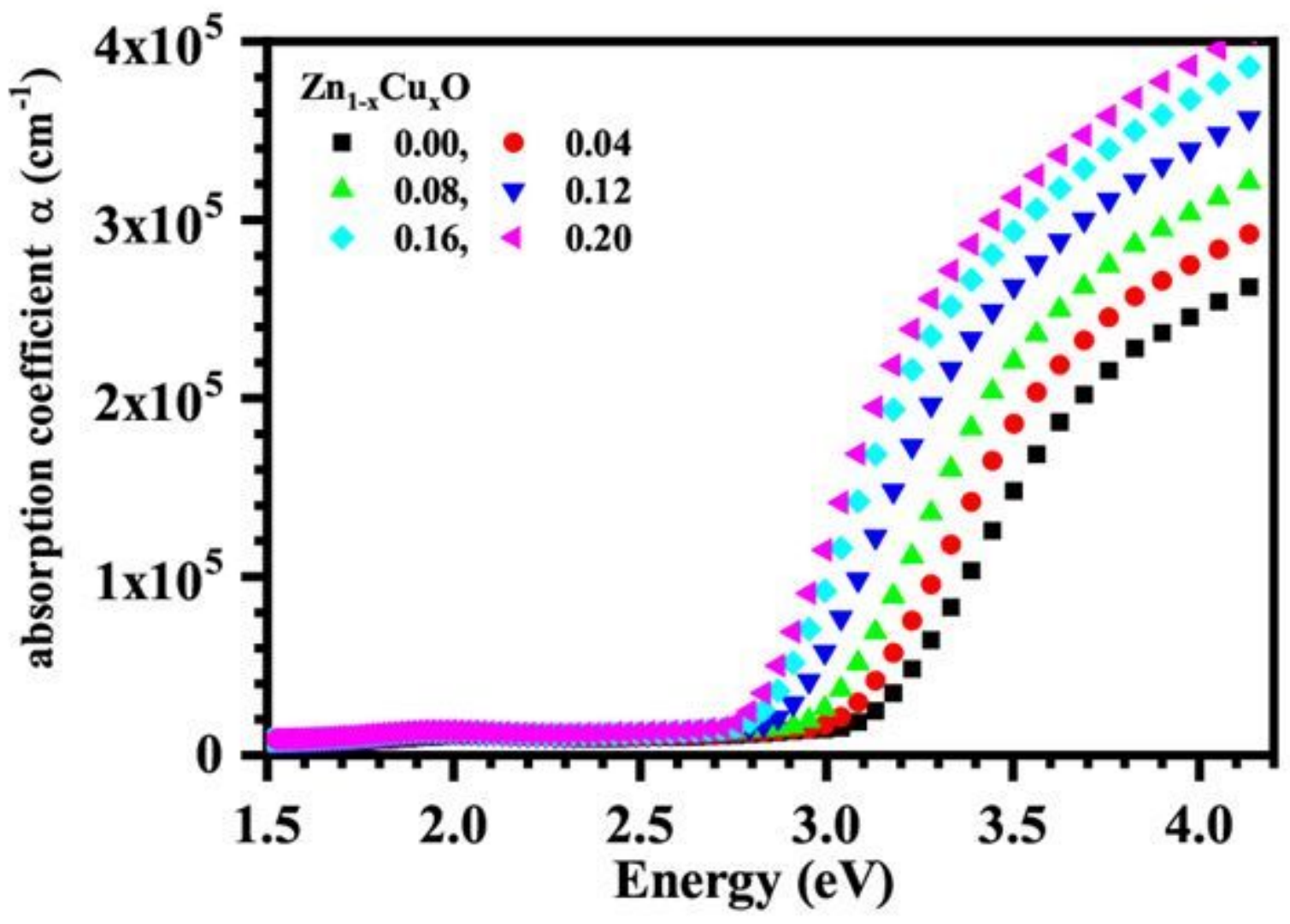

Figure 12

The absorption coefficient of $\mathrm{Cu}$ doped $\mathrm{ZnO}$ thin film samples with different $\mathrm{Cu}$ concentrations varies with photon energy extracted from SE measurements. 


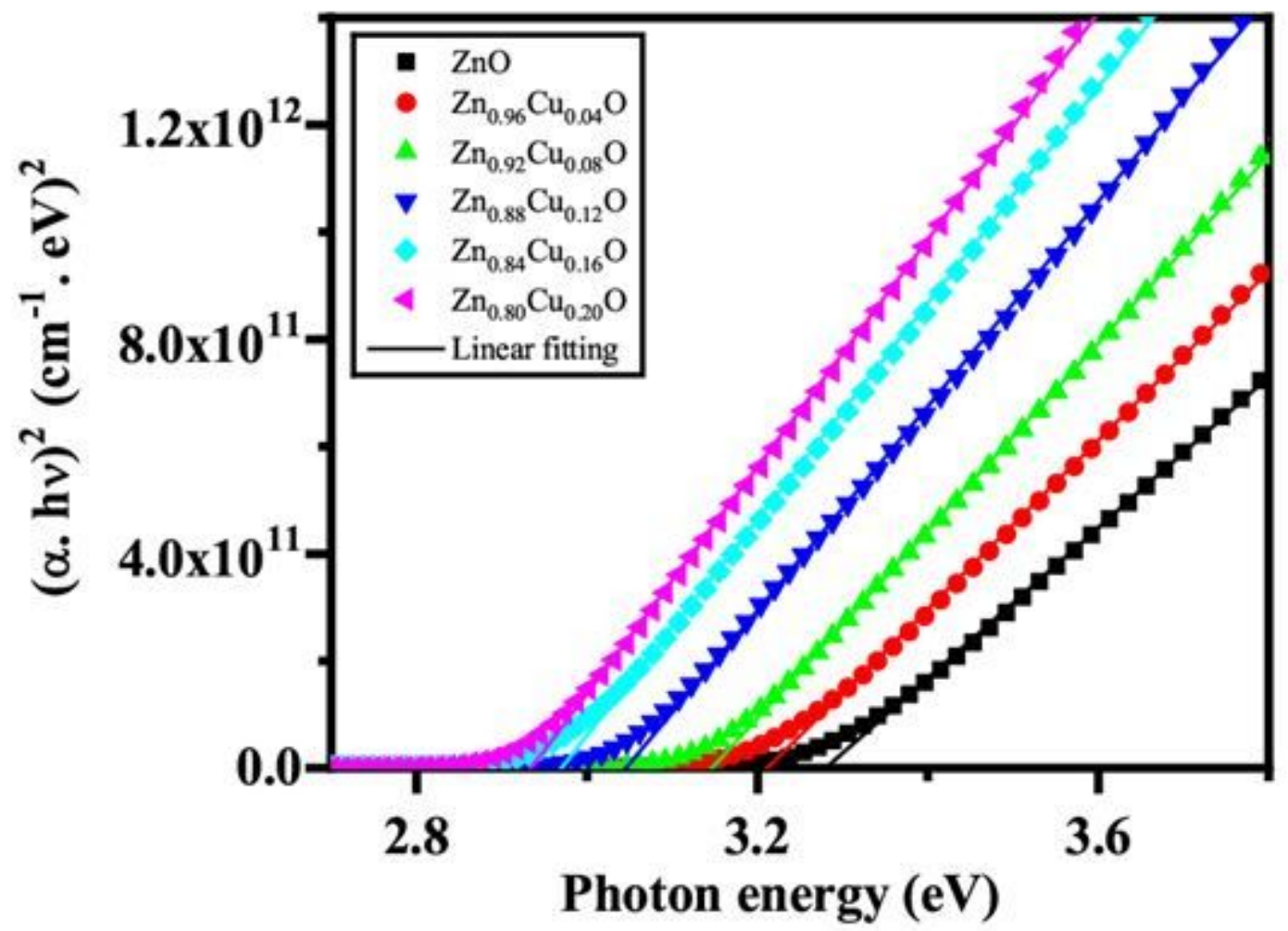

Figure 13

For nanocrystalline $\mathrm{Zn} 1-\mathrm{xC} \mathrm{CuxO}$ films with different $\mathrm{Cu}$ contents the variation of (ahv)2 as a function of photon energy (hv) is depicted.

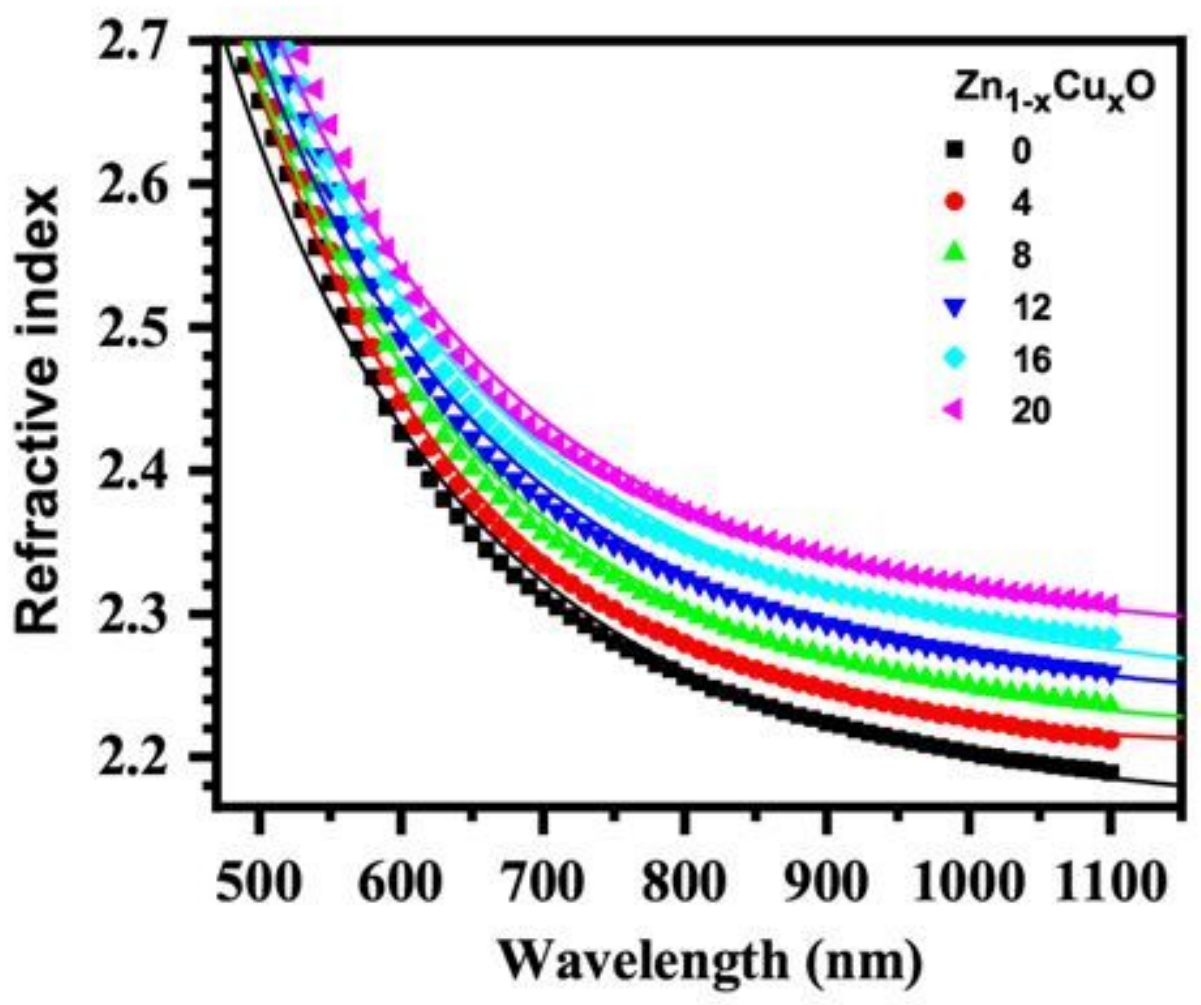


Figure 14

The wavelength dependence of the refractive index of the as-deposited nanostrcutured $\mathrm{Cu}$-doped $\mathrm{ZnO} \mathrm{Cu}$ concentrations $0,2,4,8,12,16$ and 20 at. \%.

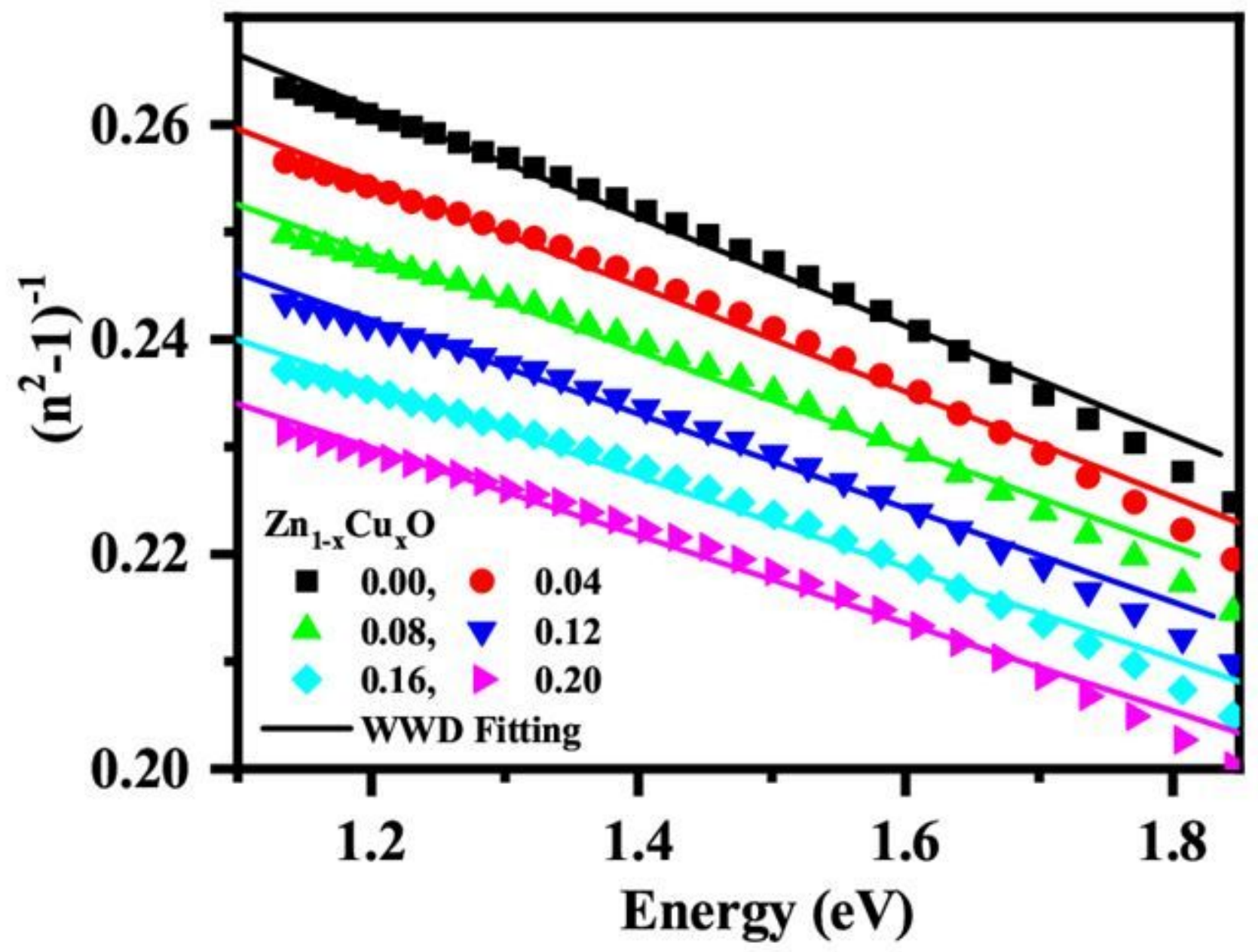

Figure 15

graphical representation of the refractive index factor (n2-1)-1 against incident photon energy (hv)2 for the undoped and $\mathrm{Cu}$ doped $\mathrm{ZnO}$ nanocrystalline thin films. 